\section{AN OVERVIEW OF DISCOURSES \\ ON KNOWLEDGE IN POLICY: \\ THINKING KNOWLEDge, POLICY AND CONFLICT TOGETHER}

Michal Sedlačko and Katarína Staroňová ${ }^{1}$

Comenius University Bratislava

Abstract: Around the world, there is a growing interest among policy scholars and practitioners in the role of knowledge in relation to public policy. These debates are accompanied by some confusion about what is meant by knowledge or evidence, as well as controversies around the role of scientists and suspicions of increasingly technocratic decision making. Our aim is to provide a useful overview of the major debates in this paper, and to trace six dominant discourses in current research that address the role of scientific knowledge or expertise in the policy process. We distinguish evidence-based policy making, knowledge utilisation, policy learning, knowledge transfer, social construction of knowledge and boundaries, and knowing in practice as separate discourses. We show how they differ in their understanding of knowledge, of the problem to solve in terms of the role of knowledge in policy, of practical implications, as well as in their understanding of public policy and in their ontologies and epistemologies. A condensed and structured representation serves as a basis for conducting comparisons across discourses as well as to open ways for analysis of strategic associations between the discourses. We hope to contribute to extending the discussion of knowledge in policy into the realm of epistemic politics and we suggest several avenues for future research that can draw on a range of concepts from across all of the discourses.

Keywords: knowledge and policy, evidence-based policy making, knowledge utilisation, policy learning, social learning, knowledge brokerage, boundary work, practical knowledge, epistemic politics

1 This work was supported by the Slovak Research and Development Agency under the contract No. APVV-0880-12. "Knowledge Utilization in Production of Policy Documents in the Policy Process"
MICHAL SEDLAČKO - Comenius University Bratislava, Faculty of Social and Economic Sciences, Institute of Public Policy and University of Applied Science FH Campus Wien, Public Management • michal.sedlacko@fh-campuswien.ac.at

KATARÍNA STAROŇOVÁ - Comenius University Bratislava, Faculty of Social and Economic Sciences, Institute of Public Policy•staronova@fses.uniba.sk

Central European Journal of Public Policy

Vol. 9 - № 2 - December 2015 - pp 10-53

ISSN 1802-4866

@ 2015 Michal Sedlačko, Katarína Staroňová

Licensed under Creative Commons Attribution 3.0

\section{INTRODUCTION}

In the recent years the calls for evidence-based policy making have resulted into more attention paid to how evidence is generated, brought into policy, and used. The literature has become quite broad and divided across a range of scientific communities. Although a consensus on the influence of scientists on policy outcomes remains beyond reach (Keller 2009), there is an increasing number of theories and empirical studies using a wide range of concepts to construct narratives of the links between policy processes and knowledge.

In this paper, we trace six primarily academic "lowercase d" discourses that address the role of scientific knowledge or expertise as well as other forms of knowledge in the policy process. The aim of this ordering attempt is, on the one hand, to provide a useful overview of the major debates on knowledge in policy. On the other hand, we intend to show how individual discourses differ in the ways they understand knowledge, the problem to solve in terms of the role of knowledge in policy, as well as implications for practice. We also aim to provide a condensed and structured representation that serves as a basis to understand strategic associations between the discourses as well as to conceptually order the relationships between various directions of analysis. We further suggest strengthening the research into the role of knowledge in policy into the area of epistemic politics and we briefly sketch several potential avenues of analysis that can draw on a range of concepts from across all of the discourses.

We attempt to hold the theoretically somewhat overloaded term "discourse" lightly. We start from an understanding that discourse represents "a specific ensemble of ideas, concepts, and categorizations that are produced, reproduced, and transformed in a particular set of social practices and through which meaning is given to physical and social realities" (Hajer 1995: 44). We 
find the notion of an ensemble important; this suggests that the ideas, concepts and categorizations are ordered into intelligible relationships. Nevertheless, adhering to an ontology of social practice, discourses are seen by us as neither objects, nor closed systems or social structures. Instead, they exist as ordering attempts only through their articulation - and cannot be seen as separated from action (cf. Dryzek 2000). In our understanding, discourses are somewhat looser and possibly contain more internal tensions than "frames" (Schön and Rein 1996), but they can serve as projective (Bryson 1981) schemata of interpretation (Laws and Rein 2006) in the sense that they - together with materia arrangements - help construct and renegotiate the somewhat durable realities that make particular actions more sensible, or probable, than others (see also the notion of "meta-narratives", Roe 1994). (Thus it would also be problematic to claim that we describe discourses as they "are"; indeed, we also conduct an ordering attempt.) Neither would we frame the ensembles we identified as "paradigms"; that term seems to imply relatively fixed (dominant) worldviews, manifested in unreflected thought styles, beliefs or even pre-rational schemes of interpretation and action. We focus on academic discourses of policy making, but at the same time do not think it is possible to entirely separate academic and practitioner discourses; indeed, academics help enact the objects of which they speak.

Methodologically, we have not followed rigorous discourse-analytical methods but used several flexible procedures to arrive at a provisional ordering of discourses, as presented in the following sections. First, in the literature, both academic journals and official documents that implement the ideas of a discourse in practice, we tried to identify what could be the backbones of ensembles of ideas, concepts and categorizations in the form of a metaphor, "code", logic, or struggle that is central to the discourse (for more details see also Table 1). Specific concepts, with at least partially stabilised meanings, are often tightly linked to this backbone. Second, we tried to construct boundaries between these individual ensembles with the use of two heuristics: one of a conflict between central metaphors or logics, and one of interpretive distance from the stabilised meanings of concepts crucial for the discourse. Nonetheless, the discourses presented should not be seen as easily demarcated and entirely independent. It is also perhaps important to note that in order to construct discourses as "ensembles of ideas, concepts and categorizations", it is important to establish relationships between ideas or concepts and identify groupings of arguments. Such work can cut across individual works, i.e. we do not assume that a publication is by default a consistent structure of arguments belonging to exactly one discourse. Also, the list of discourses presented here is not exhaustive: additional discourses on, e.g., knowledge management or governmentality (power/knowledge) could be added; we focused on the six mentioned above due to their tighter relation to policy making.

The first discourse draws on a surge of interest in what has been described as evidence-based policy making (EBPM), defined as the systematic use of the best available evidence to improve policy output (Section 2). Although EBPM writings endow scientific knowledge with particular truth-producing qualities, many of them discuss and challenge the alleged privileging of this one particular voice. The second discourse consists of accounts examining the various uses and pathways of research findings (Section 3). The third discourse on policy learning deals with the mechanisms and patterns of the "travel" of particular ideas (Section 4). The fourth discourse, "knowledge transfer", unites accounts that conceptualise science and policy/politics as different social systems, cultures, communities or social worlds that need to be "bridged" (Section 5). Its aim is to understand what makes boundary or intermediary organisations and activities (such as knowledge brokerage) effective. The fifth discourse, developed particularly while studying environmental policy, develops accounts that show how boundaries between scientific and non-scientific knowledge are strategically constructed by coalitions of actors (Section 6). It also suggests changes towards democratisation of policy making, typically by involving citizens in these processes. Lastly, the sixth discourse is a transposition of the "practice turn" in social sciences onto the work of decision makers (Section 7). Its objective is to understand what different forms of knowledge play their part in the conduct of a policy-making practice. In the discussion section (Section 8) we provide a synthesising overview and comparison of the six discourses, discuss their compatibilities, and sketch a notion of discourses linking into strategic "apparatuses". The concluding section (Section 9) formulates some recommendations for research focused on the realm of epistemic politics, one that goes beyond the traditional preoccupation with issues of knowledge and policy in the dominant discourses.

\section{EVIDENCE-BASED POLICY MAKING: PRODUCTION OF POLICY-USABLE SCIENTIFIC KNOWLEDGE}

Evidence-based policy making (EBPM) is a "rational" approach towards decision making attempting to base it on valid "information", "data" or "facts" acquired by means of acknowledged knowledge gathering and analysis methods. In literature focusing on improving the quality of output through the use of scientific knowledge, EBPM has been described as a "problem-solving", "instrumentalist", or "technical" model (cf. Haas 1992). This model is to be dis- 
tinguished from "opinion-based" or ideological policy making by appealing to rationality and what Wildavsky (1979) calls "speaking truth to power".

In the early 1970s Campbell formulated an "experimenting society", one of the first important visions of rational decision making by politicians. Based on hard-headed tests (experiments), Campbell (1991) sought to minimize bias by providing causal inferences about effect of social reforms. The notion corresponds to an evidence-based society where, besides experimentation, a wide range of evidence derived from applied research and evaluation is used. The new focus on an instrumental use of knowledge also meant a return to an expectation that social sciences and their results should be "useful".

Over the past twenty years EBPM has spread internationally (Head 2010) and the use of evidence for policy development and evaluation is now firmly established in countries like US and UK, although similar activities are seen also at the EU level, for example in the form of obligatory project evaluations, with experiments and quasi-experiments as preferred designs. Recent studies are showing a shift towards EBPM also in Central and Eastern European countries (e.g., Mikulskiene 2013 for Lithuania). Various policy fields and sectors have been subject to EBPM, including health and medicine (Rosenberg and Donald 1995, Gray 1997), education (Mosteller et al. 2002), criminal justice (Sherman et al. 2007), and labour market policy. The term was originally coined when the Tony Blair government came to power in 1997 and pledged to modernize policy making through more accountability in the decision-making process (Cabinet Office 1999a, b). One of the earliest statements on the nature of evidence-based policy was made in the Cabinet Office White Paper outlining the modernising agenda by placing research and analysis at the centre of decision making: political decisions were to be "based on a comprehensive and foresighted understanding of evidence" (Cabinet Office 1999a). The slogan "what matters is what works" became to signal the end of policy making based on political ideology (Nutley et al. 2007).

The principle of finding out "what works", the key metaphor of EBPM, has informed a number of recent governmental guidelines and support materials to enhance the production and use of evidence in policy making. Another indicator of accelerating demand for evidence is the recent proliferation of professional associations producing evidence as well as organisations that establish evidence standards and identify studies that provide the strongest evidence for decision and policy making, part of the so-called "evidence movement". For the UK, Clark and Holmes (2010) highlight the following aspects: a) adoption of government guidelines in support of good practice in using research findings and advice from researchers; b) "science and engineering assurance" reviews carried out by the Government Office for Science to evaluate and help im- prove how major departments use research findings in policy; ${ }^{2}$ c) institutional changes, primarily the establishment of chief scientific advisers in a majority of governmental organisations, so that research findings of appropriate scientific quality are used; and d) uptake of analysis and use of evidence among the core skills for civil servants in the Professional Skills for Government competency framework (in development since 2003). In this sense, EBPM is also associated with the rise of popularity of the "new public management" discourse and the structural changes in public administration that have followed (see also Nassehi et al. 2007; Pons and Zanten 2007).

EBPM aspires to "help people make well-informed decisions about policies, programmes, and projects by putting the best available evidence at the heart of policy development and implementation" (Davies 2004: 3; cf. EC 2001, 2008). Reiterating and sharpening the concerns of earlier knowledge utilisation literature (see Section 3), EBPM-oriented scholarship places the following questions into focus:

- What counts as evidence? What types of information are more used in policy making? It seems that more information is now being provided to policy makers, and that systematic reviews ${ }^{3}$ are seen as more useful than single studies.

- How is quality of evidence assessed (and by whom)? How is contestation, uncertainty or lack of consensus around evidence dealt with? Is there a hierarchy of evidence? Randomized controlled trials ${ }^{4}$ and systematic reviews are proclaimed by some governments as the gold standard in applied research and evaluation.

- How is evidence generated and brought into policy? In what activities or stages of reaching a policy decision, with what intentions of individual actors and effects is evidence used? For example, building on Weiss, Estabrooks

2 For more details, see http://www.dius.gov.uk/go-science/science-ingovernment/science-engineering-assurance.

3 Systematic reviews aim to exhaustively summarise available research results. Unlike a literature review, a systematic review starts with a clear question to be answered or a hypothesis to be tested. The reviewer then locates all relevant published and unpublished studies (not only the best known, but all that are relevant), explains how these were identified and obtained, and highlights any known gaps. The quality of the studies and the potential bias are then assessed through the methods which have been used to produce them. Finally, the results are synthesized. A protocol tends to guide the whole process to achieve maximum transparency, transferability and replicability. (See also Badger et al. 2000)

4 Randomized controlled (or clinical) trials represent all experiments where random assignment of intervention tests the effectiveness and provides information about adverse effects. Rigorous random allocation into two (or more) groups is needed to minimise potentis bis and statistical power. 
(1999) recognises direct, indirect and persuasive uses of research in policy, while Tingling and Brydon (2010) suggest that evidence can be used to make, inform or support a policy decision.

- What are the factors affecting the use of evidence? Several types of answers are provided, focusing also on the format of the evidence such as length, language used, presence of a nontechnical summary etc. but also on the links between actors producing and actors using evidence, as well as on the context of the policy decision such as Weiss's (1999) 'four Is': interests, ideology, information and institutions.

Nonetheless, what is meant by evidence is by no means clear in the literature A number of terms are used such as policy advice, policy analysis, intelligence, expertise, scientific knowledge, social science, applied research, evaluation, or evidence. There have also been intense controversies over what qualifies as "rigorous" or "credible" evidence (Donaldson et al. 2009). In this respect, two views can be identified. The conventional, narrower or conservative view claims that evidence should be independently produced through systematic reviews, meta-analysis and robust experimental research and be verifiable (Pawson 2006; Davies et al. 2000). Authors taking a broader view argue that in a democratic society rigorous scientific knowledge is only one of legitimate "voices" and "lenses" (Head 2010). Also, a more diverse array of research methods is permissible, focusing not only on "what works", but on a wider variety of questions such as "what is the nature of the problem", "why does it occur" and "how might it be addressed" (Nutley et al. 2007: 13). Nevertheless, in this discourse, the term "knowledge" most often refers to scientific or expert knowledge. That indicates a hegemonic position of scientific knowledge as compared to other types of knowledge at least on the normative, if not empirical, level as it is scientific knowledge that most closely exemplifies the specific criteria of rationality postulated by EBPM. It is argued that two features distinguish scientific/expert knowledge from other types of knowledge (Boswell 2009): a) institutional affiliation and qualifications of its producers, and b) characteristics of the knowledge itself. First, the producers of expert knowledge need to demonstrate their qualifications through academic training, position in a relevant institution, or list of publications. The primary institutional loci are thereby universities, policy analysis units of government departments or international organizations, and research institutions (including think tanks). Second, expert knowledge must employ methodologies that ensure its soundness. That also means that not all scientific knowledge fulfils the validity and usefulness criteria equally well - a research or "evidence hierarchy" (Davies et al. 2000 Higging and Green 2008) is constructed, with a bias in favour of experimen- tal research designs such as randomized control trials, large-sample studies, as well as econometric modelling, comparative data, and causal inference. The criteria of policy relevance correlate with quality criteria used to judge quantitative research. Systematic reviews occupy a specific position, as they are proposed as a solution to the problem of timing, i.e. scientific research taking too long compared to policy cycles to be able to deliver results in a timely fashion. In fact, we are witnessing a rapidly growing amount of literature on how to conduct systematic reviews of existing findings (Pawson 2006, Sager 2007).

The implied superiority of scientific knowledge and the instrumental rationality of its use have been targeted by scholarly critique, particularly in the context of the managerial reforms focusing on effectiveness, efficiency and value for money as experienced in the UK. Long ago, Cohen and Lindblom (1979) suggested that relying on scientific findings introduces a somewhat naive and dangerous expectation of conclusiveness and impartiality. The very possibility of achieving reliable causal knowledge of social processes and mechanisms for the purposes of designing and legitimising societal interventions - as compared to the knowledge in, say, areas of medical science - is being questioned (Sanderson 2000). In addition, social-scientific findings are often contradictory, inconsistent or incommensurable, and even some of the reviews commissioned by the government have been labelled as "quick and dirty" due to their hasty preparation and poor scholarship. Parsons (2002: 44) states that "EBPM must be understood as a project focused on enhancing the techniques of managing and controlling the policy-making process as opposed to (...) improving the capacities of social sciences to influence the practices of democracy". It can thus be seen as an expression of a technocratic style of policy making (cf. Fischer 1990). In that sense, concerns have been raised about the construction of an expert discourse that excludes indigenous, practical, and ordinary knowledge. As a remedy, Shulock (1999: 241) suggests that evidence and scientific research serves best "not as a comprehensive, problem-solving, scientific enterprise, but as a contributor to an informed discourse" and thus as an instrument of a democratic rather than a decision-making process. That might involve a shift from the narrow instrumentalism of EBPM towards what Smith (1996) termed "evidence society", in which democratic debate is valued.

\section{KNOWLEDGE UTILISATION: TRACING THE PATHWAYS AND DIFFERENT USES OF RESEARCH FINDINGS}

The second discourse on the interaction of scientific knowledge and policy consists of accounts focusing on ways of using research findings in policy and 
the pathways through which they get there. This discourse developed over the 1960s and particularly in the late 1970s in the USA in response to the paradox that the results of large research programmes had not found their way into policy formulation - namely in a situation of increasing budgetary pressures and growing need for accountability of public funding. It was Havelock (1969) who called for a 'science of knowledge utilisation', bringing this discourse into existence.

The first main notion rests on the understanding that there are various factors influencing how and when research findings "travel". Weiss (1979), on of the key scholars in the then-emerging knowledge utilisation and innovation diffusion literature, developed a set of six models describing different patterns of research utilisation. These models are used to understand how evidence and knowledge is thought to shape or inform policy. The first two models describe instrumental use of research findings by policy makers but with differing directions of influence. First, in the knowledge-driven model, policy is led by research and knowledge is directly applied in policy formation. In the second policy-driven model, which is a reiteration of Havelock's (1969) problem-solver model, research follows policy: policy issues (in particular in relation to an impending policy decision) shape research priorities, while consensus on goals is required. These models of instrumental utilisation have been further elaborated. A more recent reiteration is offered by Landry et al. (2001): the "sciencepush model" (where research advances and finds its way into practice, while users are considered to be passive recipients) stands in opposition to the "demand-pull model", where user demand for usable and relevant research influences research priorities through tenders and contracted research, research agendas or funding schemes. ${ }^{5}$ Knott and Wildavsky (1980) formulated a mode to measure the influence of research results over a particular policy decision with six stages forming a chain consisting of reception, cognition, discussion, reference, effort (adaptation), and influence. Others have, nevertheless, problematized the assumption of linearity as well as the wide range of possible types of influence (some of them perhaps empirically untraceable such as research findings shaping routines or seeping into tacit knowledge; cf. Davies et al. 2005). It has also been recognised that research impacts policy through pathways that are unpredictable, contingent and non-linear (Gabbay and le

5 Landry et al. (2001) developed several additional models. The organisational interest model is similar to the demand-pull model, nevertheless research utilisation focuses on the rules and culture of the recipient organisation. The dissemination model places propagation activities and mechanisms in the forefront. Finally, the interaction model integrates other models in a manner similar to Havelock in that it tries to include the different factors of research utilisation in one model.
May 2004). Some researchers suggest that research findings are becoming increasingly intertwined with other factors along these pathways (Carden 2005) causing complex problems in attribution. It has even been suggested to examine societal or organisational transformation rather than (intentional, targeted and discrete) application of research findings. (What happens in detail on the boundary between science and policy is the subject of the third discourse, presented in Section 5.)

Weiss (1980), nevertheless, observed that instrumental use was (at that time) quite rare, a conclusion reconfirmed recently by, e.g., Owens et al. (2006) and Boswell (2009). This is the case even where governments set up in-house research units (Nutley et al 2007). The situation when government-commissioned research stays unused was termed by Shulock (1999) as "the paradox of policy analysis". Various resistances inherent to governmental organisations have been described to explain this phenomenon. When used, inputs from external experts "overload collective decision processes, undermine consensus and coalition maintenance, and disrupt incremental decision-making patterns," or contradict "the experience-based legitimation of most bureaucracies" (Dror 1979). Canary (2010) identified two structural contradictions in the use of policy-relevant knowledge, which she terms "policy legitimation versus allocative resources" and "control versus autonomy". That research produced or commissioned by governments is not being used to inform policy profoundly challenges the instrumentalist account of knowledge utilisation.

The second main notion of this discourse is therefore that in addition to instrumental or problem-solving functions, research often takes on other, symbolic functions in policy making. In Weiss's (1980) political model, research is used (selectively) to legitimise a premeditated decision. Research findings are used strategically in the service of political interests and values. The fourth model, the tactical model, describes how bureaucratic politics uses research, e.g., to build an image of responsiveness or to delay an undesirable decision Thus, research is used as a political tool, in a way that is unrelated to actual problem solving or to the substance of the research. Also for Boswell (2009), expert knowledge fulfils two other distinct functions in policy making: enhancing the legitimacy of organizations ("legitimizing knowledge"), and lending credibility to their policy preferences ("substantiating knowledge"). Similarly, Weible (2008) identified three uses of expert knowledge - instrumental use, political use, and learning (corresponding to conceptual use). Clark et al. (2011) distinguish between enlightenment, decision and negotiation as purposes of knowledge use. Stevens (2011) observes that in policy processes scientific arguments require political support, and it would seem that available scientific knowledge gets selected and used not primarily when it fits the instrumental 
needs of policy, but when it fits the political interests of policy actors. Instead of its "contents", knowledge is valued for its power to signal authority, validity or legitimacy of organizational decisions, structures and practices. Bocking (2006) implies that the role of science in policy making is going to differ depending on the political context, i.e. whether the dominant pattern in politics is conflict between interest groups or consensus seeking. ${ }^{6}$ Based on this he suggests that the form of scientific advice needs to adapt to the context.

The fifth model of Weiss (1980), the enlightenment model, describes an indirect relationship between science and policy when research findings (rather slowly) propagate through various channels across society, raise public awareness and influence problem framing in policy ("conceptual use"). In this model, research is not necessarily in line with values and goals of policy makers or with immediate policy concerns. Likens (2010) also observes that in the absence of political interests, scientists can contribute to creating public awareness and thus put pressure on political actors. Lastly, in Weiss's (1980) interactive model, there is no position of influence and it is referred to a more complex and disorderly interaction and mutual collaboration between knowledge producers and knowledge users. It typically includes skills pooling, mutual consultation and understandings without scientists dominating the process. This latter model was perhaps best developed in a recent discourse on knowledge transfer and knowledge brokerage (Section 5)

\section{POLICY LEARNING: TRAVEL OF IDEAS ACROSS POLICY SYSTEMS}

Long ago, Heclo (1974) suggested that knowledge acquisition and utilization could lead to better understanding and improvement of existing policies, and thus "learning" can cause policy change. In contrast to the EBPM discourse, which primarily focuses on the criteria of permissible evidence, the policy learning discourse evolved around the intent to study how knowledge about particular policy instruments, institutional arrangements or even ideas and ideologies "travel" between or across policy systems or policy fields.

The policy learning discourse is rich on concepts used to describe this travel or movement of policy knowledge across time and space. "Policy diffusion" studies the patterns of movement of ideas, or a "successive or sequential adoption of a practice, policy or programme", from a perspective that implies "spreading, dispersion and dissemination of ideas or practices (across space

6 Renn (1995) recognised four styles of using scientific expertise: adversarial, fiduciary, consensual and corporatist. See also the study of Jasanoff (1998) on national styles of decision making. and time) from a common source or a point of origin" (Stone 2001, pp. 4-5; cf. Eyestone 1977). Such a perspective seems to go beyond a process in which decision makers more-or-less rationally or voluntarily imitate or modify the tools that seem to work elsewhere by implicating structural forces at play. Favouring structural explanations even more, the term "policy convergence" (Bennett 1991) implies a dominant pattern of "increasing similarity in economic, social and political organization between countries that may be driven by industrialization, globalization or regionalization" (Stone 2001, p. 6).

Nevertheless, such explanations do not entirely pay attention to the mechanisms through which the travel of knowledge or ideas takes place. The four causes of policy convergence in Bennett (1991), i.e. penetration, emulation, harmonization, and elite networking and policy communities, do not explain, perhaps with the exception of the latter, how a particular decision maker came across the knowledge which his or her decision is based on. Thus, the concept of "lesson drawing" (Rose 1991, 1993) that addresses questions such as who, when and how draws proper lessons across time and space (where lessons can be positive, prescribing what ought to be done, as well as negative, in terms of what not to emulate; Rose, 1993, pp. ix-x). For Rose, lesson drawing is an intentional exercise involving research in order to gather knowledge and information and learning from either policy makers' own or others' experience, often conducted by public officials (cf. Heclo 1974). The normative effort to improve policies lies in the promotion of institutional implementation and procedural improvement of this intentional exercise. Thus similarly to EBPM, evidence based on rational systematic search for best possible options and lesson drawing becomes some of the options for policy intervention. More broadly, "policy transfer" (Dolowitz and Marsh 1996, 2000) refers to "a process in which knowledge about policies, administrative arrangements, institutions, etc. in one time and/or place is used in the development of policies, administrative arrangements and institutions in another time and/or place" (Dolowitz and Marsh, 2000 , p.5). In this view, lesson drawing is only at one end of the continuum of three different processes of transfer: voluntary transfer (or perfect rational lesson drawing), negotiated transfer (under bounded rationality) and direct coercive transfer.

Nevertheless, there is an ontological point of contention within the policy learning discourse. Positivist models of policy diffusion and policy transfer, initially based on literature studying diffusion of innovation, assume that policy instruments, scientific facts or ideas exist as fully formed, stable objects travelling from one place to another (or from centre towards periphery), to be accepted, modified or rejected within a new (stable) institutional, cultural etc environment. This understanding was questioned already by Schön (1973) 
and recently also by the policy translation literature (e.g., Clarke et al. 2015) The empirical counter-argument is that the object travelling is "fluid, mutable, changing itself and the environment as it moves" (Freeman 2006, p. 371). Thus, in line with a more constructivist understanding, both the object as well as its destination are in a process of dynamic structuring.

The changes caused by the "travel" of knowledge or ideas about policy to their destinations are understood as policy change or policy learning. In his account of learning in macroeconomic policy, Hall (1993) sets out three levels of policy change: a) adjustment or modification of policy instruments with unchanging policy objectives (incremental learning, or Glasbergen's (1996) technical learning); b) change in the overarching goals that guide policy (conceptual learning, or May's (1992) social learning); and c) exchange of underlying paradigms through which problems are framed, and thus a genuine shift in policy beliefs with fundamental implications for the choice of policy instruments (corresponding to May's political learning)

The literature universally acknowledges that the process of learning is neither automatic nor simple. Jenkins-Smith and Sabatier (1993) argue that "knowledge does not suddenly appear, become universally accepted" (p. 47) Quite the opposite, the impact of information on policy making is most likely to be slow, "indirect, delayed, and general" (Dunn, 2004, p. 58). Thus, scientists have, besides processes and outcomes as well as indicators and research methods measuring the successes and failures of policy learning and lesson drawing, extensively focused on the role of actors and the social structures in which they participate (cf. Biegelbauer 2007). This included a shift of attention from fixed entities producing knowledge (such as universities or policy analytical units) toward the role of more loose, flexible and informal networks, to recognise that stakeholders such as think tanks, civil society, citizens and others have increasingly been involved in producing policy-relevant knowledge. Sidney describes this trend in the following words: "national policy ... increasingly finds policy formulation to occur outside of government offices - that is, in think tanks and within the loose networks of advocacy and interest groups that together with government officials make up policy communities" $(2007, \mathrm{p}$. 86; cf. Weingart 2001).

Considerable efforts have also been put into researching various types of social structures - such as networks or communities - in which policy makers and other actors participate. Sabatier (1988) attempts to integrate knowledge utilisation (what he calls the "enlightenment function" of policy analysis) with processes and interactions among the actors in an advocacy coalition framework (ACF). He stresses the role of beliefs that create conflict and opposition, but also possibilities for alliances among actors representing different groups, organizations and institutions "who share a set of normative and causal beliefs and who often act in concert" (Sabatier, 1988: 133). The shared beliefs and assumptions, however, are not static, but transform over time or are replaced by others. Experience, knowledge and information accumulated from past policies lead to such changes, i.e. learning. It is also important that several competing advocacy coalitions usually emerge within a policy subsystem, coalitions that compete for access to policy and institutional resources. Policy learning then depends not only on factual knowledge but also on insights gained from social interactions between actors and groups (Jasanoff 1997). It would seem that for achieving policy learning, "pluralist and corporatist" networks (Coleman and Skogstad 1990; Coleman and Atkinson 1989) are more favourable, since they provide their members with "steady interactions with other [members] who will hold, to an extent, different policy beliefs and preferences" (Montpetit 2007). However, it has also been suggested that under the network view knowledge is used tactically according to policy actors' interests (Weiss 1977) Nevertheless, networks and communities serve not only to spread knowledge, but also to motivate action and define interests (Hall 1989). Overall, the move towards networks and communities as objects of analysis also instigated a turn from rational and problem-solving organizations towards recognition of the role of social learning and the formation of groups and collectives around beliefs and ideas (in addition to ACF also "epistemic communities", Haas 1989, or "discourse communities", Hajer 1993, cf. "elite networking and policy communities" as factors of policy convergence in Bennett 1991), or shared practices ("communities of practice", Lave and Wenger 1991, Wenger 1998).

Nevertheless, despite the four decades of struggling with concepts such as "policy learning" or "policy change", it still remains conceptually unclear what elements constitute such learning (Bennett and Howlett 1992) or when a policy change constitutes a case of learning (Biegelbauer 2013). Another point of critique focuses on the actors with whom the beliefs of advocacy coalitions originate: "Sabatier takes the view that the policymaking process, in terms of agenda-setting and other phases, is dominated by elite opinion" (Parsons, 1995: 197).

\section{KNOWLEDGE TRANSFER: "BRIDGING THE GAP BETWEEN} TWO COMMUNITIES" THROUGH INTERMEDIARIES

An image of two separate communities, knowledge producers and knowledge users, and of a multi-dimensional gap between them hampering knowledge transfer, turned out to become one of the dominant images for knowledge in 
public policy. It is implied that science and policy are two different worlds with different languages, values, rewards systems etc. - and thus the gap is not only a knowledge gap, but also, inter alia, a cultural, motivation, reward, immediacy or terminology gap (Caplan 1979; cf. Haddow and Klobas 2004). This discourse has a similar practical starting point as the knowledge utilisation literature (see Section 3), i.e. the observation across numerous policy areas and political debates that research findings and scientific knowledge are not being taken into account and passive diffusion does not seem to work. The main assumption of this discourse is a missing connection or a "knowledge gap" in the research-to-policy chain, requiring a focus on intermediary actors and structures between science and policy. The leading metaphor of "bridging the gap" signifies the necessity of linking these two separate worlds or communities, and the two-community model requires a key actor "positioned at the interface between the worlds of researchers and decision makers" (Ward et al. 2009: 267).

A third, intermediary or boundary actor was proposed already by Heclo (1974) under the name "policy middle men", by Kingdon (1995) under the term "policy entrepreneurs", and more recently by Pons and Zanten (2007) as "knowledge entrepreneurs". For more institutionalised boundary actors also the term "boundary organizations" (Hoppe 1999; Hoppe et al. 2013) has recently gained currency. Knowledge transfer or translation activities have traditionally been conducted by policy advisors, a function which has since the 1970s been increasingly transferred from governmental organisations to policy consultants or think tanks (Dror 1979; Page and Wright 2007). As shown in Section 4, the role of think tanks and other sources of external policy advice such as ministerial advisers, private consultants and interest groups has been growing. This discourse, nevertheless, describes actors and activities specialised on transferring (scientific) knowledge, often under the term "knowledge brokerage".

This discourse is crowded with terminology enabling different perspectives on the dynamics between various actors and sources of knowledge. "Research dissemination" or "knowledge translation" (Dobbins et al. 2009) are used to address the need to conduct and communicate research in ways that users will find helpful, while the concept of "knowledge intermediation" (Davies et al. 2008) describes the managed processes of promoting and guiding the interaction between actors and different sources of knowledge. For this "messy engagement of multiple players with different sources of knowledge" Davies et al. (ibid.) suggest the term "knowledge interaction", while the term "science-policy interfaces" (van den Hove 2007) signifies the variety of possible relationships between scientists and other actors in the policy process. The term "knowledge transfer" describes a linear sequence of operations along the chain from producing research findings towards their use in decision mak- ing. To include all these concepts under a single umbrella concept, ottoson (2009) suggested the term "knowledge-for-action theories", while Bielak et al. (2008) speak of a " $\mathrm{K}^{*}$ ". But whereas the knowledge utilization discourse (Section 2) rather sees scientific knowledge spreading or diffusing somewhat passively from producers towards the various uses in policy, the knowledge transfer discourse sees this travel of knowledge as an active and managed activity, requiring established linkages between actors and transformations of said knowledge along the way.

Recent literature suggests that knowledge brokers are actors who help connect existing knowledge such as research findings (or knowledge producers themselves) to actors with knowledge needs, i.e. knowledge users such as policy makers (cf. Bielak et al. 2008; Ward et al. 2009). Their activity is sometimes described using economic terminology as creating markets for knowledge and connecting demand with supply (Stone 2002; Bielak et al. 2008); other times it is likened to social network building. Beyond this narrow understanding (subsumed by Pregernig 2004 under the heading "transactional framework"), knowledge brokerage can mean "activities that enhance access to knowledge within a society" (through a "social change framework"; ibid, pp. 6-7). Overall, knowledge brokerage has been suggested to have three dimensions (Task Force 1996; cf. Pregernig 2004; Michaels 2009; Ward et al. 2009; Meyer 2010):

- knowledge capture, transfer and translation, in which knowledge brokers act as knowledge managers,

- development of knowledge-based networks, in which knowledge brokers act as linkage agents,

- development of capacities to produce and use policy-relevant knowledge, in which knowledge brokers act as capacity builders.

Knowledge brokerage is an activity that a range of possible actors can conduct. An obvious choice could be the producers of knowledge such as research institutes, a strategy for bridging knowledge and policy that Stone (2002) labels as supply-side approach, with the alternatives being a demand-side and "policy-currents" approach. Nevertheless, increasing attention has been given to individuals or organisations that specialise in this activity, such as scientific advisory bodies or university technology transfer offices. ${ }^{7}$ Holmes and

7 Sometimes even whole countries are analysed from the perspective of knowledge brokerage activity (Oldham and McLean 1997), suggesting that such activities do not have to be conducted ersilies, but that they can have a certain nation strategic importance and be covered by state "projects" 
Lock (2010: 33) confirm the need for specific staff "to overcome problems of lack of mutual understanding". They suggest that the staff conducting these roles should actively provide advice to practitioners while also be involved in research activities. It would seem that the tacit knowledge of researchers is valuable in translating findings and giving advice and cannot be easily transferred to others and that knowledge brokers require a close familiarity with both worlds. One of the problems identified by this discourse is that scientists are typically not incentivised to publish in outlets where findings have a higher chance to be taken up in practice but are not relevant for a scientific career (Shanley and López 2009; cf. Owens et al. 2006).

Critics of this discourse have claimed that Caplan's model of two communities has been adopted in a way reminiscent of the functionalist sociology of Parsons or Luhmann, i.e. with an implicit understanding of science and policy as self-contained, auto-poietic social systems. More recent explanations, developed particularly in the area of environmental and sustainability policy, try to understand the relationships of science and policy in terms of interaction between cultures (Kothari et al. 2009, Clark and Holmes 2010; cf. "epistemic cultures" in Knorr-Cetina 2007), "stable patterns of interaction" (Clark and Holmes 2010), "social worlds" (Guston 2001) or "communities of practice" (cf. Wenger 1989) instead of between two social systems. Although the differences might be subtle, these different theoretical conceptualisations result in somewhat different practical recommendations.

Clark and Holmes (2010) suggest that a more useful explanation focuses on the differences between social structures and cultures. ${ }^{8}$ They identify a range of constraints for research to better inform policy, among them the researchers' lack of knowledge what policy makers to contact and how, lack of funding for policy-relevant research and incentives to communicate research findings to policy makers, as well as policy makers' difficulties in accessing research findings or seeking expert advice. They try to understand these constraints as embedded in the specific and different cultures in which researchers and policy makers are placed. Therefore, as the authors suggest, to be effective, "the various initiatives need to be developed with understanding and sensitivity to differences in the social structures and cultures of people who work in research and in policy" (p. 761). They also cover a number of practical concerns, arguing, for instance, that "more opportunities are needed for advisers, pol-

8 Referring to Hughes et al. (2002), by social structure they mean the "recurrent and stable patter in people's interactions and their relationships" (Clark and Holmes 2010:752), and by culture the "learned paters for thiking, feling and acting" (Hughes et al. 2002:41), that nevertheless have both non-material and material components. icy people, researchers and experts to meet, establish and maintain contact (ibid.).

Whereas Clark and Holmes lean towards a positivist understanding of individual actors in social contexts and structures, Guston's (2001) understanding, in contrast, would be more social constructivist. He conceptualises science and policy as different "social worlds" and studies the boundary organisations that produce mutually instrumental knowledge accountable to both of these social worlds. A successful boundary organisation needs to internalise the boundary negotiations and "speak differently to different audiences" ( $p$ 405). Among the examples of boundary organisations listed by the literature are scientific advisory bodies, university technology transfer centres and even ad-hoc processes such as scientific assessments. Hoppe (2009), studying the discourses of boundary arrangements to identify seven distinct discourses and sets of practices, confirms a plurality of co-existing actors and arrangements in the policy-making landscape. Studying the parameters of knowledge in boundary arrangements, Cash et al. (2003; cf. Glaser and Bates 2011) suggest that the chance that a particular piece of scientific knowledge will be taken up by policy grows when the knowledge fulfils certain criteria. Not only has it to be perceived as credible (i.e. as scientifically adequate) by relevant stakeholders, but at the same time it has to be salient (corresponding to policy makers' needs) and legitimate (respecting the views and values of various stakeholders). Unfortunately, these three criteria are fundamentally conflicting, Cash et al. claim. When knowledge systems manage to produce knowledge fulfilling these requirements, they typically feature active and iterative communication between experts and policy makers, translation to overcome misunderstanding between the various communities, and active mediation of conflicts to increase transparency and legitimacy. They advocate institutionalisation of these functions in boundary organisations that, similarly as Guston (2001) suggests, need to face the challenge of dual accountability. The success of boundary organisations seems to rest on problem definition (i.e. "wicked" vs. tame), stage of the policy process, and the extent to which the actors are willing to blur the separation of science and policy to achieve coproductive relationships (Hoppe et al. 2013).

Another line of critique focuses on whether the increase in interaction between science and policy is producing positive effects only. Weingart (1999) and Hoppe (1999) point out the dialectical process of "scientization" of policy and "politicization" of science, as well as the "intensification of boundary transactions" and the emergence of what Hoppe calls "strategic science" (Hoppe 2005, p. 204; cf. "Mode 2 science" of Nowotny et al. 2003). 


\section{PROBLEMATIZING "KNOWLEDGE" AND "BOUNDARIES" THROUGH} EMPHASISING THEIR SOCIALLY CONSTRUCTED NATURE

The fifth discourse, strongly influenced by the social studies of science (SSS) or science and technology studies (STS), stresses that what counts as knowledge in a particular situation is to be thought of as socially constructed. Therefore, one of the main notions of this discourse is that researchers should not be concerned with how to theoretically draw the boundary between scientific or expert knowledge and non-scientific or lay knowledge (or the systems of science and policy, for that matter), but observe how that boundary is drawn in practice and how the drawing process serves strategic aims (Gieryn 1983, Jasanoff and Wynne 1998, Jasanoff 2004, Hoppe et al. 2013; cf. Keller 2009). The empirical, practical drawing of the boundary produces significant strategic effects such as stabilisation of hierarchies between various forms of knowledge as well as between experts and non-experts (or citizens), attributing and distributing cognitive authority and monopolising epistemic resources, or demarcating an area as factual and thus free of contestation. Cortner (2000) describes how the institutions of science and scientific policy advice exclude, e.g., experiential knowledge or values possessed by citizens (similarly see also Fischer 2000 Adams 2004; Owens et al. 2006; Petts and Brooks 2006). Nevertheless, "objective science" is not necessarily to be found in "factual" areas: Jasanoff (2010) observes how scientists involved in policy making incorporate subjective judgements into their claims while invoking their own expert authority. Also Bader (2014) suggests that although the legitimacy of science rests on its production of descriptive and explanatory accounts, it can never be devoid of normative or expressive claims and thus fulfil the ideal of objectivity and value neutrality (cf. Keller 2009). With regard to a decision-making process, we then see that conflict not only plays out around the choice of one of the alternatives, but also around establishing the criteria that define valid and permissible knowledge to base these "rational" alternatives on, as well as around the actors included in or excluded from articulating valid knowledge claims and their criteria.

The boundary between science and "non-science" is not inherently given. Instead of being rooted in the nature of the knowledge or the processes of its production or use - note that Weingart (2001) observes that empirically there seems to be no clear separation in time or content between the activities of science and policy - the boundary is (strategically) constructed through manifold processes. To capture related discourses, practices, as well as organisational arrangements, Hoppe (2005) suggests "boundary work" as an umbrella term Boundary work nevertheless encompasses not only the processes of bound ary construction (demarcation) but also establishing interaction across differ- ent (scientific, policy-making) practices and thus can also have a coordinating function (Hoppe 2009). This latter function is, for the purpose of this paper covered by the knowledge transfer discourse.

Boundary construction can be traced in discursive practices, in connection to competing coalitions of actors bound by particular shared discourses, storylines, or policy frames (cf. Hajer 1995). It has been suggested that scientific facts possess "interpretive flexibility" (Collins and Pinch 1982, cf. Miller 2004) and thus can be taken up by competing policy frames. It has also been suggested that it is not the rationale of facts, figures and information that justifies the decisions of policy makers, but rather the use of literary devices such as symbols, characters, plots and metaphors (Stone 1997) which elicit positive or negative reactions. In other words, the same scientific fact entering the discursive practices of different interpretive communities (e.g., science and policy) will be interpreted differently by and play different roles in these communities, a perspective captured by the concept of "boundary objects" by Star and Griesemer (1989).

Nevertheless, the positions developed in this discourse have also been used to dismantle some of the notions of the network/community view (see Section 4). For example, the theory of "epistemic communities" (Haas 1989, Adler and Haas 1992, Haas 1992) assumes, emphasising a more individualistic explanation, that members join these groups based on cause-and-effect and normative beliefs about a particular problem. Empirical studies challenged this notion and showed how assembling an epistemic community is a complex process occurring along the lines of scientific disciplines, economic interests or political ideologies (Jasanoff 1996; Lahsen 2004; cf. Meyer and Molyneux-Hodgson 2010).

These arguments favour ontologies based around structural or institutionalist explanations. The boundary can also be seen as embedded in the "structures and procedures" that give an "institutional expression" to the rationalist view of the role of science in policy making (Keller 2009: 29). ${ }^{9}$ Brand and Vadrot (2013: 208) coined the term "epistemic selectivity" to describe how

9 Keller (2009) distinguishes between rationalist and positivist views of the role of science. The rationalist view sees goals as defined by policy, while science is brought in instrumentally, as "neutral competence", to inform policy making. Boundaries between them need to be guarded to prevent politicisation of science, and situations in which they interact need to be controlled. The positivist view, on the other hand, sees science as a resource in resolving policy controversies (with the prerequisite that science is assumed to reflect the truth) and thus "defines the terrain (for policy debate) that is factual" (ibid: 30). In Lindblom (1959), Keller finds arguments for suggests to use the agreement of all participants as a measure. 
political economy produces particular forms of state incorporating strategic apparatuses that "make possible the separation of what may be characterised as scientific from that which is not". On the other hand, on the level of material practice a number of studies have shown how construction and stabilisation of a boundary takes place through documents or technical devices - see, e.g., the notion of a "chain of inscriptions" (Latour 1986) or "scripts" or "programs of action" (Akrich 1992; Latour 1988) - or visually, through particular imaging techniques. So, instead of the objectivity of science, researchers should examine science's "claims of objectivity" (Keller 2009).

The discourse offers numerous possibilities for placing power and a broader notion of politics into the centre of analysis, depending on the theoretical framework and ontology chosen. For example: How is hegemony of one discourse/discursive position or policy frame achieved and stabilised to such an extent that it is taken for granted and escapes reflection or critique? How do actor coalitions around particular discursive "storylines" (Hajer 1995) and "state projects" (Jessop 1990) form? How do different problem frames imply different solutions, questioning the objective basis for adjudicating alternatives (Hajer and Laws 2006)? How do scientific actors contribute to formation of re gimes or state apparatuses with the power to determine what knowledge is truthful (Brand and Vadrot 2013)?

What does this discourse offer for the design of policy processes, given its strong descriptive purpose? Jasanoff (1990) reminds us that trying to set a reliable boundary between scientific and non-scientific knowledge is misguided. Also, as Keller (2009: 37) suggests, the "lack of a clear boundary between science and policy should not be troubling" if balance between technocratic and democratic decision making is maintained. That means that it is necessary to widen the interaction between scientists and decision makers to include also citizens and other actors. Decisions so reached should be less controversial and more acceptable as good decisions (Jasanoff 1990). Various concepts have been used to describe such an arrangement. Even Wildavsky (1979) does not rule out public participation in the "hybrid of social interaction and intellectua cogitation" that he calls policy advice, although in his account expert knowledge plays a privileged role. Bader (2014) speaks of "associative democracy" and a blurred boundary between cognitive and normative knowledge. In international relations, Bäckstrand (2003) also argues that citizens should not be seen as recipients of policy only but as actors in their own right, and as stakeholders in respect to scientific knowledge that is to be treated as global public good. Cortner (2000) and Bäckstrand (2003) conceptualise "civic science" as a means to critically reflecting on the risks of technocratic governance and to improving participation, representation and democracy in decision making.

\section{KNOWING IN PRACTICE: RECOGNISING THE CONNECTIONS} BETWEEN VARIOUS FORMS OF KNOWLEDGE

Informed by the literatures on knowledge and knowing from organisational sciences as well as the 'practice turn' in sociology, the sixth discourse aims to re-acknowledge the importance of practitioner knowledge. Contrary to scientific knowledge, the knowledge of service delivery practitioners or local authorities as well as the technical knowledge of program managers and coordinators (cf. Lipsky 1980) relates to awareness of what to do as well as how where, when and why to do it. It is knowledge of goals, of ends and means, rather than of facts. Parsons in this vein suggests that policy formulation should rely on "imagination, intuition and experience rather than the great 'tool' of coherence building, information" (2004: 55).

Besides "professional knowledge" or "practitioner knowledge", over the last decade the term "practical knowledge" gained currency. Practical knowledge or know-how (as opposed to know-what, cf. Ryle 1949) enables the carrying out of a particular practice and includes schemes of pre-rational understanding and interpretation, sense-making, or practical judgement. Such knowledge resists verbalisation and codification as it often escapes conscious reflection - thus it is also termed "implicit knowledge" ${ }^{10}$ Reckwitz (2003: 292) recognises three types of implicit knowledge mobilised in practices: interpretive understanding, methodical knowledge, and motivational-emotional knowledge. Schatzki (2012) recognises four types: general understandings, practical understandings, rules, and teleoaffective structures. Wagenaar (2004) deals specifically with how rules are known in administrative practice. Although it was already Weber who suggested that knowledge of procedural rules represents "a special technical learning which the officials possess" (1946: 198), Wittgenstein and Polanyi made the important observations that rules are grasped in a way that is not an interpretation and does not require a conscious, intellectual activity or even a choice: rules become part of practice obeyed "blindly" and constitute an understanding that cannot be articulated. Wagenaar (2004) observes that rules (as abstract generalisations) are never automatically applicable to a concrete situation but have to be interpreted ad hoc. In fact, rules and situations are co-constitutive: rules are used to understand the situation, while the situation is used to realise the rules. "This knowledge, which [actors] have picked up through formal training and informal socialization, tells them how to interpret the situation and where to go" (ibid: 650).

10 Polanyi's "we know more than we can tell" (1962: 4) applies here. 
Recently also a distinction between knowledge and (practical) knowing has been made. This distinction brings attention to the social or communal character of practical knowledge in practice. While knowledge can be understood as a resource "deposited" in individuals, knowing requires a community in which social practice is situated and only becomes visible in doing. ${ }^{11}$ Nicolini et al. (2003: 3) write that "knowing precedes knowledge, both logically and chronologically", and identify the following characteristics of knowing: it is (1) situated in a system of ongoing practices of action, (2) mediated by artefacts and (3) rooted in a context of interaction. Knowledge that exists through such knowing is "acquired through some form of participation, and it is continually reproduced and negotiated; that is, it is always dynamic and provisional" (ibid: 8). Similarly, Wagenaar observes that "knowing is social in the sense of being rooted in, being part of, a largely unarticulated reservoir of background knowledge" (2004: 650). Knowing is thus "not separable from doing, and learn ing is a social" - and we might also add, material - "and not merely a cognitive activity" (ibid.). This has also been acknowledged by Lave and Wenger (1991; Wenger 1998) in their work on "communities of practice", a concept supposed to bridge between cognitive and social aspects of learning, where knowledge is "integrated and distributed in the life of the community" (Nicolini et al. 2003 15). Also studies focusing on "local knowledge" or "lay knowledge" suggest that such knowledge represents "intense contextualized knowledge of people in their local environments" (Petts and Brooks 2006; cf. Wynne 1991). As such it is embedded in the world around and shared informally within social groups and communities. Adams (2004) points out that one of the effects of the rationalis creed of expertise is an overemphasis on individual knowledge over community or shared knowledge.

1 Cook suggests that "knowledge is knowing at rest" (personal communication). Freeman and Sturdy (2014) elaborate on the distinction between "embodied knowledge" and "inscribed knowledge", on the one hand, and "enacted knowledge", on the other. The latter is the know " on the " on the transient (lasting only during enactment), and collective.
Figure 1 Classification of knowledge into different forms

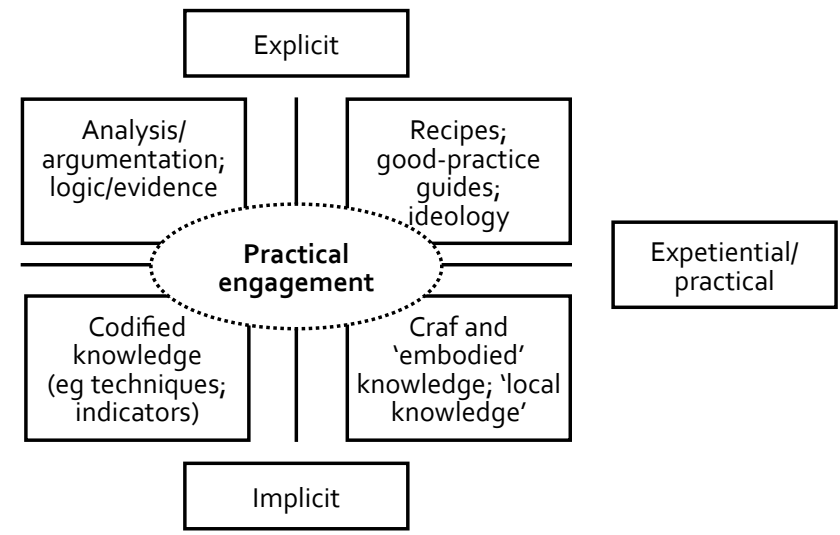

Source: Healey (2007)

An important part of this discourse are classificatory schemes consisting of pairs of opposing concepts such as know-how/know-what (Ryle 1949) or tacit/ explicit (Polanyi 1962). (See also Figure 1). Building on later work of Polanyi, Cook and Brown (1991) distinguish between tacit and explicit knowledge and suggest that these "are two distinct forms of knowledge (i.e. neither is a variant of the other); that each does work the other cannot; and that one form cannot be made out of or changed into the other". Furthermore, "each form of knowledge can often be used as an aid in acquiring the other" (ibid; emphasis in original). A theme that Cook and Brown identify is that these various forms of knowledge are not separable in the sense that a successful practice would require only one or the other. Tacit and explicit knowledge are tightly linked and this understanding might serve to resist an exaggerated focus on explicit scientific or expert knowledge in policy processes. As Wagenaar (2007: 432) observes, "[d]ata, conclusions, as well as the grounds for those conclusions are constituted by the shared expectations, beliefs, values, routines, and practices of the members of a culture; 'constitutive' indicating that the shared background knowledge 'creates the very possibility of certain activities'”. It is the integration of multiple forms of knowledge that might be key to achieving better policy outcomes - and this understanding is resonant in a lot of recent literature (cf. Flyvbjerg 2001; Nutley et al. 2007). Thus, in addition to scientific knowledge this includes also practical judgements and intuition; not only explicit, formalised knowledge but also local or lay knowledge. Colebatch suggests a perspective centred on the concept of policy work, stressing that "[i]t is not simply that there are multiple forms of knowledge to be brought to bear 
on a clear problem" (Colebatch 2006: 317), but there are also different forms of knowing. These forms of knowing come to the fore in participatory and interactive exercises, displacing more traditional problem-solving types of knowing and associated explicit knowledge.

There are several difficulties with the operationalisation of the precepts put forth by this discourse. First, there is no theoretical or empirical guidance for conceptualising transfer of knowledge between different practices. Second, because of the focus on observable practice, which is treated as collective and situated accomplishment of competent (or increasingly competent) participants-practitioners, a number of aspects become occluded. The researcher acquires a view of practice "as it is", but does not see structural inequality resulting from that practice, or legitimate interests of actors, in other sites. Sites and actors effectively isolated from the observed practice are invisible. What Lukes (1974) terms as the second and third dimensions of power, i.e. the exclusion of actors from conflict and the prevention of interests from being formed and articulated, cannot effectively be researched. That also implies structura selectivity in terms of the knowledge permitted into a policy-making practice, unless the researcher relies also on other approaches. Combined with the fact that it is conceptually impossible to envision a possible "working" but as yet non-existent practice, this strictly limits the possibility of thinking knowledge integration or its costs.

\section{SIMILARITIES, DIFFERENCES, STRATEGIES: A DISCUSSION}

The discourses presented in detail in the sections above are summarised in Table 1 . We list there the central metaphor organising the discourse, forming the "backbone" of the "ensemble of ideas, concepts and categorizations", and further we present in a condensed manner the primary problem to solve (see also further below), the proposed solution, and the main criticisms raised against the discourses.

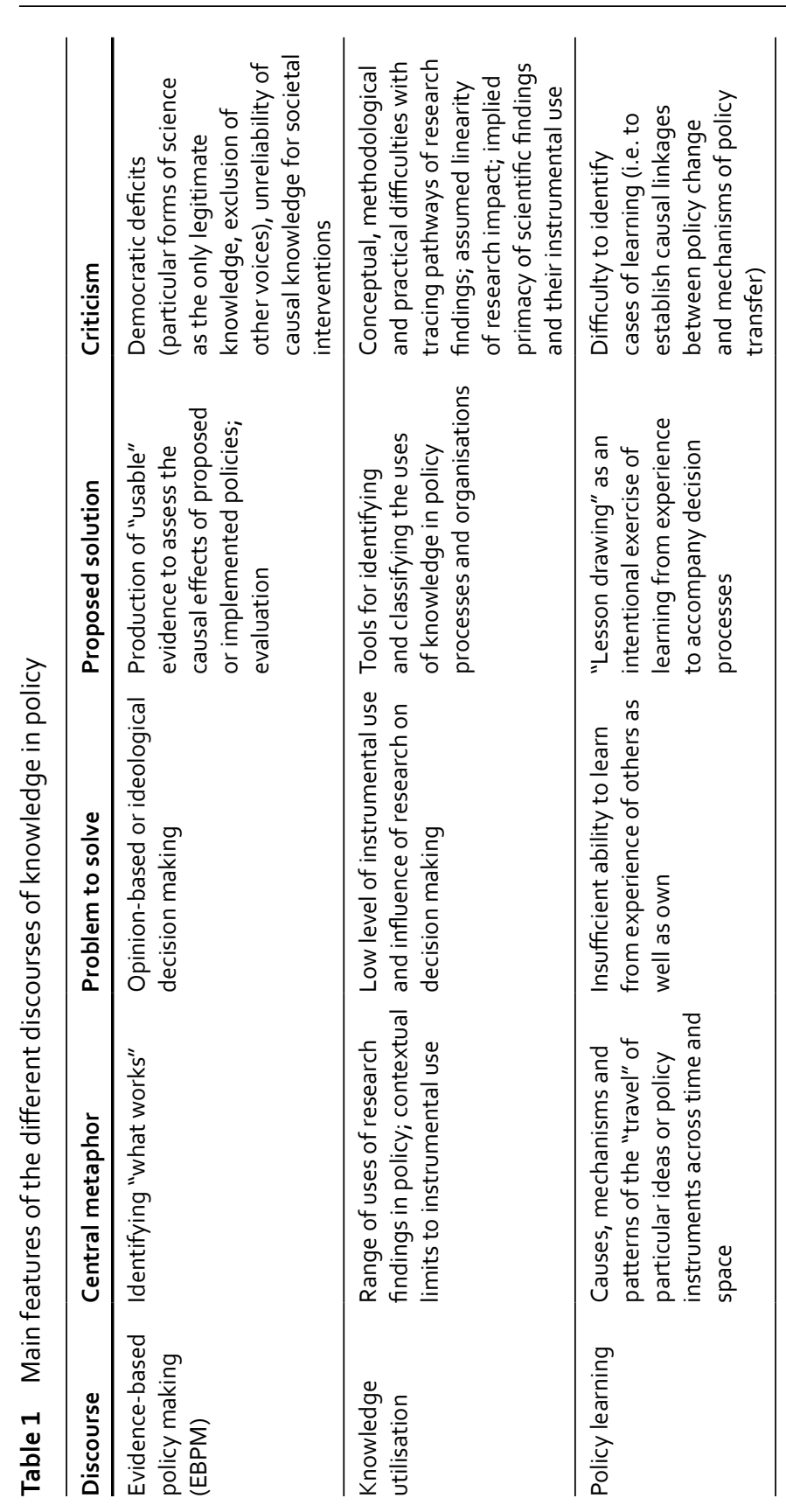




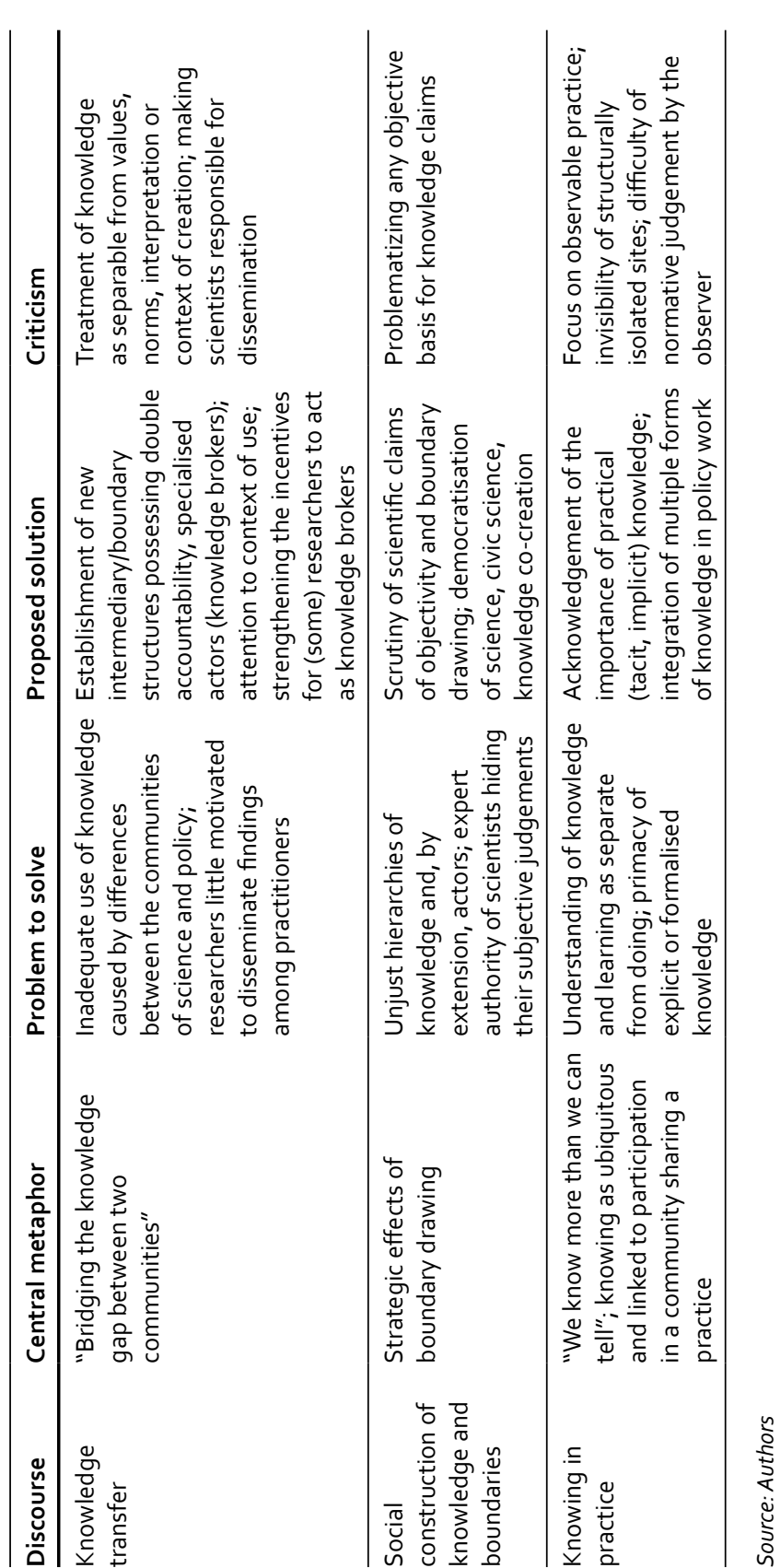

To better understand the similarities and differences between the discourses presented above we used several axes of analysis consisting of sets of binary oppositions or scales. First, we inquired whether the purpose of research conducted within the frame of the discourse is primarily prescriptive or descriptive (see also the columns "problem to solve" and "proposed solution" in Table 1). Second, we checked whether the nature of policy making dominant within the discourse is understood as rational problem solving or rather as including also negotiation of interests and influence of power effects on the tackling of uncertainties ("puzzling and powering"; Hall 1993). The third axis is concerned with the forms and nature of the knowledge that is primarily drawn on in policy making. Even though a simple dichotomy of "scientific knowledge only vs. (also) other forms" could be constructed, we recognise several forms of scientific knowledge and types of scientific rationality (cf. Hoppe 1999): a "narrow" form concerned primarily with "facts" or claims about the causal effects of an intervention fulfilling scientific criteria of quality; "procedural" scientific knowledge referring to problem structuring, planning, budgeting, evaluation, data management and similar methods and procedures to ensure the rigour of policy making; and an "enlarged" concept of scientific rationality including also the functions of societal critique, participatory validation of scientific procedures or results, and structured deliberation between and elicitation of views of various societal actors (particularly citizens) in support of a policy-making process. In the knowledge transfer discourse, we also mention "translated scientific knowledge", i.e. scientific findings reinterpreted and reframed, simplified and aggregated, and reformulated and reformatted by knowledge brokers to increase their compatibility with the logics of policy. In addition to scientific knowledge other forms include, e.g., ordinary citizen knowledge, practical knowledge and intuition of policy makers etc. (see also Section 7). What we understand as "form" in this respect implies that knowledge is not "neat as a pin" but it is indivisibly entangled with practices, patterns of social organisation, resource allocation and subjectivation. Fourth, we tried to generalise the forces or factors favoured by the explanations in the individual discourses, i.e. whether they are rather structural such as institutions, social organisation, historical determinism or economic forces, on one hand, or individual - agency realised through various kinds of resources, on the other. Lastly, we tried to identify any epistemological and ontological commitments shared across each of the discourses.

It should be noted that applying these binary categories is an exercise in construction of oppositions, unification, and classification - and as such it tends to eliminate complexity and subtle differences among individual arguments for the purpose of providing a simplified schema. Such a move inher- 
ently involves power effects and should be legitimised by its purpose - beyond a simple ease of clustering/structuring our normative purpose is to voice critique against technocratic approaches to policy making and open up new avenues for critical policy analysis. Further, applying binary categories is never entirely straightforward; due to the breadth of the discourses it is often hard for one side of the axis to seamlessly describe or fully exhaust the discourse. As an example, even strongly descriptive studies contain some kind of judgement and formulate recommendations (prescriptions). Our classification should therefore rather be understood as a focus or preoccupation of the discourse, a tendency. Also, we have used these axes and their categories for analysing discourses and not their identification (see Section 1), as we consider these axes to be tools brought to bear by the observer rather than inherent or constitutive categories or oppositions around which discourses form (although it is possible that in specific cases the boundaries between the discourses correspond to these binary oppositions). The results can be found in Table 2 .

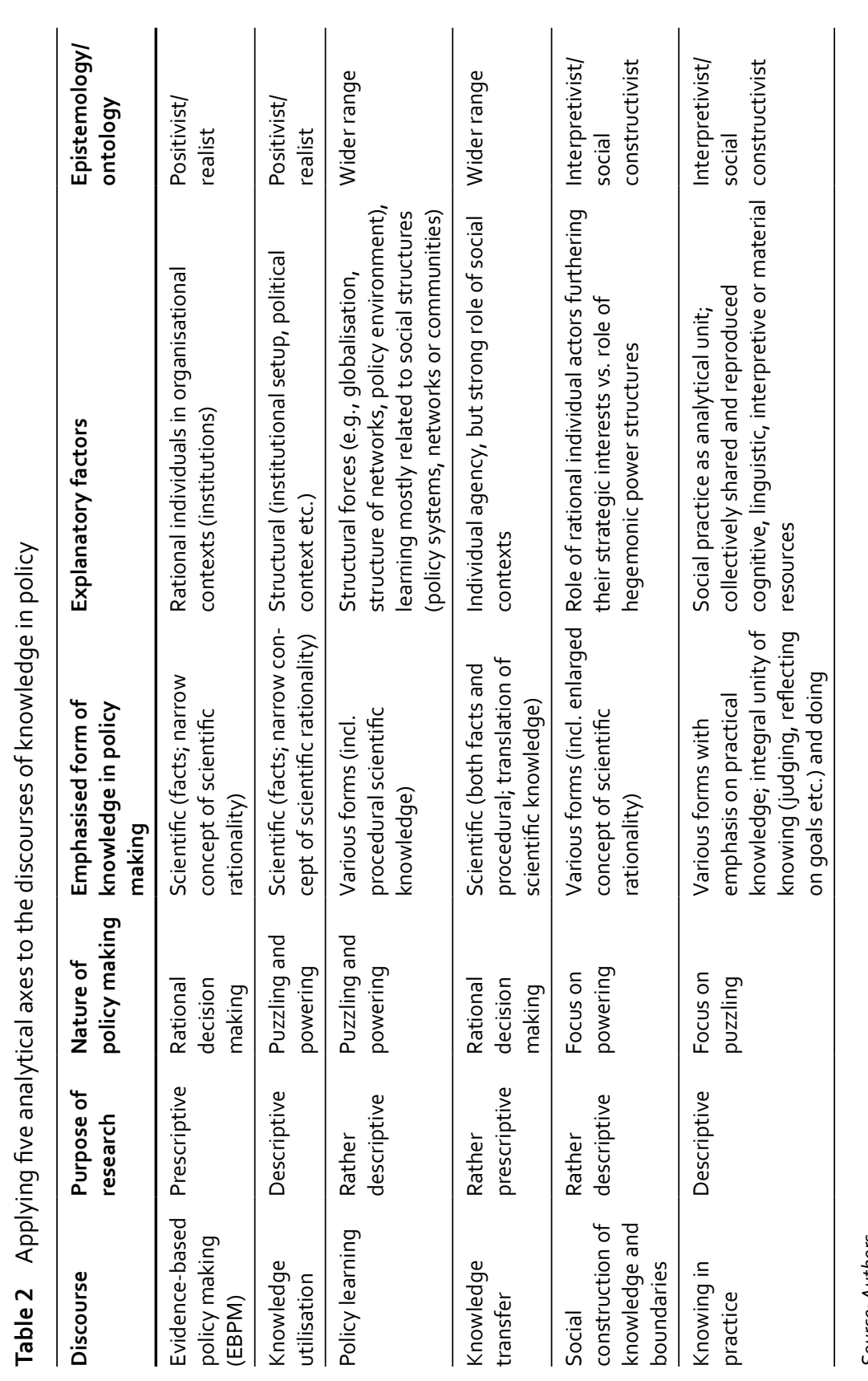


The discourses of EBPM (Section 2), knowledge utilisation (Section 3) and knowledge transfer (Section 5) share the explicit assumption that it would be possible to arrive at better policy outcomes if we were to possess more or better knowledge (or be able to render the world more knowable). External experts (such as scientists) should provide that knowledge, typically in the form of policy advice. This assumption is thus sometimes termed "knowledge gap". Nevertheless, that is by no means a recent idea. Long ago, for Weber the "technical means and calculations" (1946: 139) were the means through which rationality in decision making was enabled. Foucault describes how as far back as in the late $18^{\text {th }}$ century specific administrative mechanisms for management of the relationships between populations and their territories were developed in reliance on scientific knowledge in areas such as statistics (the "science of the state"), demography, geography, or public health (Foucault 1978; cf. de Certeau 1984, Rutherford 1999). In Table 2 some other complementarities between these three discourses can be seen; e.g., EBPM and knowledge transfer discourses share a prescriptive orientation, an understanding of policy as rationa problem solving and an emphasis on scientific knowledge. All three discourses share also the positivist assumption that science "speaks the truth" (even though it might be distorted by strategic interests of actors) and should therefore be awarded primacy in the implied hierarchy of knowledge (parts of the knowledge transfer discourse nevertheless recognise the role of interpretation)

But the discourses also seem to be strategically linked into an "apparatus" that is fundamentally transforming science as well as the policy process and the roles of various actors. The EBPM discourse seems to provide legitimacy for the primacy of scientific knowledge while telling us how science is to be conducted in order to produce "usable evidence". The knowledge transfer discourse then formulates additional responsibilities for researchers in the form of communication and dissemination of their findings and introduces intermediary actors who possess the capacity to judge as well as represent scientists' work and bring beneficial findings to actors and into decision processes. The knowledge utilisation discourse then offers a conceptual apparatus to help distinguish between "proper" (instrumental) and "improper" (symbolic, polit ical) use of research. Looking at this assemblage critically, its results include creation of markets for and commodification of knowledge, transformation of higher education towards "entrepreneurial universities", increasingly competitive and precarious working conditions for academic staff who are relabelled as "knowledge workers", as well as exclusion of non-experts from decision making. Perhaps the strategic compatibilities between these three discourses could contribute to the account of the dialectics between "politicisation of science" and "scientisation of policy" (Hoppe 1999, Weingart 2001).
It is somewhat striking that these discourses, while framing policy making as rational problem solving, do not offer conceptual tools for grasping some of the central categories of political science such as power, interests and conflict. When policy makers decide without consulting scientific evidence or outright against it, they are understood to do so on the basis of "opinions" or "ideology", or as "strategic" action with a view to their own political interests such as re-election or satisfying their clienteles through resource allocation. The political rationality of "powering" is in conflict with the aspiration for a disinterested search for truth and optimal policy solutions. Because of the positivist assumption that scientific knowledge is objective if rigorous methods are followed, and because EBPM provides a unified standard for measuring mentioned rigorousness, any conflict between knowledge claims or interests played out in the epistemic arena can be solved by comparing the "quality" of these claims-cum-evidence on the "evidence hierarchy". This also implies a singular, ultimately knowable and non-contradictory nature of reality and furthermore omits that scientific facts need to be interpreted - and can be interpreted in differing ways. These discourses are also blind to the intertwining of factual and normative claims in scientific practice and evidence; see Section 6. Conflict is transformed into a technical-administrative problem of applying the criteria for judging the quality of evidence, with the effect that some legitimate political interests will be stripped of the knowledge giving them ground and some knowledge will lose legitimacy, such as ordinary citizen knowledge or the practical intuition and skill of policy makers. Producing such technical criteria and standards is thus a move to erase the epistemic dimension of "powering" or political conflict. Thus, struggles about how to define knowledge and what forms it can take, what methods produce valid knowledge, and which actors contribute to its production, take part in its use, or are influenced by it, thus cease to be legitimately political conflicts. Over the last years there has been an increasing effort on the part of the knowledge utilisation literature (Davies et al. 2005; cf. Nutley et al. 2007; Boswell 2009) to develop conceptual and methodological tools that would help eliminate "ambiguities" of knowledge use in the policy process and help shift from legitimizing to substantiating uses of scientific knowledge.

As compared to the science-centric image of policy making shared across these three discourses, the policy learning discourse (Section 4) shows how even non-scientific factual knowledge acquires legitimacy in the policy system either by applying procedural scientific rationality (i.e. by following protocols of lesson drawing), or through its social character, by becoming a part of a "corpus" of causal understandings, beliefs, policy frames or values of particular networks or communities. There are compatibilities with the knowledge utili- 
sation literature (uses of research findings in policy) and the knowledge transfer literature (mechanisms through which particular findings travel, transform and find their addressees). Nevertheless, the policy learning discourse adds a particular sensibility towards the effects of knowledge and learning in the form of policy change as well as an understanding that policy change does not have to result from rational problem solving or negotiation of political interests but can also depends on structural forces specific to modernity or, for example, coercive relations between policy systems. The focus on learning as a result of a socially situated practice or interaction, on the one hand, and on beliefs, frames or schemata of interpretation innate to particular social structures active in the processes of policy, on the other hand, represents avenues of compatibility both with the knowing-in-practice discourse (Section 7), and with the discourse on the social construction of knowledge (Section 6). The policy learning discourse thus seems to be situated centrally, in a potentially connective and transformative position - depending, of course, on epistemological and ontological compatibilities.

It could also be argued that democracy can be fostered if the above assumptions about neutral and objective science hold, and if negotiations of epistemic criteria are shifted away from the sphere of the political into the sphere of the expert (Nutley and Webb 2000; cf. Etzioni 1968). The ideal of the separation of factual, value-neutral claims from normative claims suggests that decision makers are provided with best available knowledge on the basis of which a purely political process of formulating policy goals can take place. As opposed to the knowledge creation process, in the political process science has no authoritative claim and is only one voice among many - i.e. science facilitates decisions but does not determine them (cf. the roles of policy analysis in Hoppe 1999). These proposals are maybe not so distant from the aspirations of "civic science" (Section 6) and the proposed hybrid forms of technocratic and democratic decision making. But there is evidence that the separation between producing useful information for decision making (expert logic, "puzzling") and the democratic character of decision making (political logic, "powering") is not so easy to achieve. Over the last decades the benign and value-neutral role of scientific knowledge has increasingly been questioned by critical scholars and political activists, raising doubts whether - even notwithstanding the political processes of interpretation, framing or argument selection in the realm of policy - science can withdraw into the realm of the apolitical (Section 6). Focusing on structural and procedural aspects of power, and how science participates in them, opens a much more political and conflict-oriented view of policy making that challenges the image of separation between the expert logic and the political logic. Another way to problematize the image of a clean bound- ary is through the differing standards for what counts as valid knowledge in various scientific communities (and it might be that also non-scientific forms of knowledge cannot be kept easily on one side or the other. By extension this applies to a scientific epistemic conflict between networks in which scientists participate and which are trying to acquire access to political resources). After all, citizens' knowledge is often used instrumentally within the expert logic, although often losing in a conflict between the abstract but legitimised knowledge of scientific experts or evidence-producing organisations with global validity claims, on one hand, and the local and rich knowledge of citizens, perhaps valid only in specific contexts, on the other hand (Wynne 1996; Fischer 2000; Rice et al. 2015). As the experience with science shows, it could also be argued that separating knowledge claims from value claims is not only an unrealistic expectation but also a kind of structural violence. Foregrounding the issues of epistemic politics, power and conflict through an actor-oriented view brings into focus the epistemic dimensions of the conflict between and strategies chosen by various networks or communities, whereas a more structuralist or a more constructionist view turns attention towards structures and forces that have formative effects on institutions, interests and identities (such as the discursive mechanisms of selection between differing knowledge claims or interactions between various state projects or strategic apparatuses that stabilise the linkages between particular epistemic criteria, forms of knowledge, and actors' coalitions).

\section{CONCLUSION: KNOWLEDGE IN POLICY AND THE} QUEST FOR A DEMOCRATIC EPISTEMIC POLITICS

In this paper we attempted to identify the central academic discourses on knowledge and policy and, through their condensed and structured comparison, to contribute to the possibilities of new ways of analysis. We identified six "lowercase d" discourses: evidence-based policy making, knowledge utilisation, policy learning, knowledge transfer, social construction of knowledge and boundaries, and knowing in practice. We compared them across a range of categories, including perceived problem and proposed solution, understanding of policy making, or epistemology and ontology. Even though we understood discourses as enactments of ordering attempts in sociomaterial practice - and thus as inherently unstable, in need of constant reproduction and permanently open to change - we contributed to the literature by our own projective ordering of "existing" discourses since we believe that such a condensed representation opens some new avenues of analysis. First, we are able to conduct 
comparisons and trace similarities and links between discourses, thus bringing more starkly into the foreground the differing logics of the discourses - problems to solve, proposed solutions, understanding of policy making - that bind the "ensembles of ideas, concepts and categorizations" together. Second, such an abstract representation also starts opening ways to think of strategic apparatuses of multiple discourses and the potential strategies and power effects such apparatuses are able to manifest, a notion which we briefly discussed on the example of the transformation of science and policy under the notions of technocratic problem solving and impartial science.

Lastly, we paid attention to the political and power dimensions of the procedural and institutional arrangement of policy processes in respect to knowledge, a dimension that is not entirely in the foreground of dominant debates. We hope to have persuaded the reader of a need to expand the notion of knowledge in policy into the realm of epistemic politics. Also, we have presented discourses that may lead to further research, such as the various uses of knowledge by policy actors, forms of knowledge in policy work and practice, coping with multiple accountability demands through knowledge translation work conducted by boundary actors, institutionalisation of knowledge boundaries and hierarchies in state apparatuses, models of science-policy interactions, or links of actor coalitions and their interests to political economy This might also require new research strategies and methodological designs relying on, e.g., critical discourse analysis, organisational ethnography, shadowing, (historical) tracing of associations, and sensibility for the multiple discursive, material or institutional means through which politics of knowledge and related conflicts are being framed, led, resolved or avoided, on the one hand, but also the more sensitive quantitative tools for understanding knowledge use and actor influence beyond citation network analysis, on the other hand. With this overview we intend to make a contribution to increased exchange between scholars from across these different discourses.

\section{REFERENCES}

Adams, D. (2004). Usable knowledge in public policy. Australian Journal of Public Administration 63(1): 29-42.

Adler, E. and Haas, P. (1992). Epistemic communities, world order, and the creation of a reflective research program. International Organization 46(1): 367-390.

Akrich, M. (1992). The de-scription of technical objects. In: W. Bijker and J. Law (Eds.), Shaping Technology, Building Society: Studies in Sociotechnical Change, (pp. 205-224), Cambridge: Cambridge University Press.
Atkinson, M. and Coleman, W. (1989) Strong states and weak states: sectoral policy networks in advanced capitalist economies. British Journal of Political Science 19(1): 46-67.

Bäckstrand, K. (2003). Civic science for sustainability: reframing the role of experts, policymakers and citizens in environmental governance. Global Environmental Politics 3(4): 24-41.

Bader, V. (2014). Sciences, politics, and associative democracy: democratizing science and expertising democracy. Innovation: The European Journal of Social Science Research. 27(4): 420-441.

Badger, D., Nursten, J., Williams, P. and Woodward, M. (2000). Should all literature reviews be systematic? Evaluation and Research in Education 14(3/4): 220-230.

Bennett, C. J., \& Howlett, M. (1992). The lessons of learning: reconciling theories of policy learning and policy change. Policy sciences 25(3): 275-294.

Biegelbauer, P. (2007). Learning from abroad: the Austrian competence centre programme Kplus. Science and Public Policy, 34(9), 606-618.

Biegelbauer, P. (2013). Wie lernt die Politik?: Lernen aus Erfahrung in Politik und Verwaltung. Springer-Verlag.

Bielak, A. T., Campbell, A., Pope, S., Schaefer, K. and Shaxson, L. (2008). From science communication to knowledge brokering: the shift from "science push" to "policy pull." In: D. Cheng, M. Claessens, T. Gascoigne, J. Metcalfe, B. Schiele and S. Shi (Eds.), Communicating Science in Social Contexts: New Models, New Practices (pp. 201-226), Amsterdam: Springer.

Boswell, Ch. (2009). The Political Uses of Expert Knowledge. Immigration Policy and Social Research. Cambridge: Cambridge University Press.

Brand, U. and Vadrot, A. B. M. (2013). Epistemic selectivities and the valorisation of nature: the cases of the Nagoya Protocol and the Intergovernmental Science-Policy Platform for Biodiversity and Ecosystem Services (IPBES). Law, Environment and Development Journal 9(2): 202-220.

Cabinet Office (1999a). Modernizing Government: Green Paper. London: Stationary Office.

Cabinet Office (1999b). Professional Policy Making for 21st Century. London: Stationary Office.

Campbell, D. T. (1991). Methods for Experimenting Society. American Journal of Evaluation 12(3): 223-260.

Canary, H. (2010). Constructing policy knowledge: contradictions, communication, and knowledge frames. Communication Monographs 77(2): 181-206.

Caplan, N. (1979). The two-communities theory and knowledge utilization. American Behavioral Scientist 22(3): 459-470.

Carden, F. (2005). Making the Most of Research: The Influence of IDRC-supported Research on Policy Processes. Paper for the international conference African Economic Research Institutions and Policy Development: Opportunities and Challenges, Dakar, 28-29 January 2005. URL: http://www.idrc.ca/uploads/user-S/11085518871Making_the_ Most_of_Research.pdf

Cash, D W., Clark, W C., Alcock, F., Dickson, N M., Eckley, N., Guston, D H., Jaeger, J. and Mitchell, R B. (2003). Knowledge Systems for sustainable development. The Proceedings of the National Academy of Sciences 100(14): 8086-8091. 
Clark, R. and Holmes, J. (2010). Improving input from research to environmental policy: challenges of structure and culture. Science and Public Policy 37(10): 751-764.

Clark, W. C., Tomich, T. P., van Noordwijk, M, Guston, D., Catacutan, D., Dickson, N. M. and McNie, E. (2011). Boundary work for sustainable development: natural resource management at the Consultative Group on International Agricultural Research (CGIAR). PNAS www.pnas.org/cgi/doi/10.1073/pnas.0900231108.

Cohen, D. K. and Lindblom, C. E. (1979). Solving problems of bureaucracy: limits on social science. In: C. H. Weiss and A. H. Barton (Eds.), Making Bureaucracies Work (pp. 125-138), Beverly Hills: Sage.

Colebatch, H. K. (2006). What work makes policy? Policy Science 39: 309-321.

Coleman, W. and Skogstad, G. (1990) Policy Communities and Public Policy in Canada: A Structural Approach. Ontario: Copp Clark Pitman.

Coleman, W. and Skogstad, G. (1990). Policy Communities and Public Policy in Canada: A Structural Approach. Ontario: Copp Clark Pitman.

Collins, H. M. and Pinch, T. J. (1982). Frames of Meaning: The Social Construction of Extraordinary Science. Boston: Routledge and Kegan Paul.

Cook, S. D. N. and Brown, J. S. (1999). Bridging epistemologies: the generative dance between organizational knowledge and organizational knowing. Organization Science 10(4): 381-400

Cortner, H. J. (2000). Making science relevant to environmental policy. Environmental Science \& Policy 3: 21-30

Davies P. (2004). Is Evidence-Based Government Possible? Jerry Lee Lecture 2004, presented to the Campbell Collaboration Colloquium, Washington DC, 19 February 2004

Davies, H, Nutley, S. M. and Walter, I. (2005). Assessing the Impact of Social Science Research: Conceptual, Methodological and Practical Issues. A background discussion paper for ESRC Symposium on Assessing Non-Academic Impact of Research. St Andrews: University of St Andrews, Research Unit for Research Utilisation. URL: http:// www.odi.org.uk/rapid/Meetings/ESRC/Index.html

Davies, H., Nutley, S. and Walter, I. (2008). Why 'knowledge transfer' is misconceived for applied social research. Journal of Health Services Research \& Policy 13(3): 188-190.

Davies, H., Nutley, S. M. and Smith, P. C. (2000). Introducing evidence-based policy and practice in public services. In: H. Davies, S. M. Nutley and P.C. Smith (Eds.), What Works? Evidence-Based Policy and Practice in Public Services (pp. 1-12), Bristol: The Policy Press.

de Certeau, M. (1984). The Practice of Everyday Life. Berkeley: University of California Press.

Dobbins, M., Robeson, P., Ciliska, D., Hanna, S., Cameron, R., O'Mara, L., DeCorby, K. and Mercer, S. (2009). A description of a knowledge broker role implemented as part of a randomized controlled trial evaluating three knowledge translation strategies. Implementation Science 4(23).

Dolowitz, D. and Marsh, D. (1996). "Who learns what from whom: A Review of the Policy Transfer Literature," Political Studies, 44, 343-57.

Dolowitz, D. and Marsh, D. (2000). Learning from Abroad: The Role of Policy Transfer in Contemporary Policy-Making. Governance 13 (1): 5-24.

Donaldson, S. I., Christie, C. A. and Mark, M. M. (2009). What counts as Credible Evidence in Applied Research and Evaluation Practice? London: Sage.
Dror, Y. (1979). Think tanks: a new invention in government. In: Weiss, C. H. and Barton, A. H. (Eds.), Making Bureaucracies Work (pp. 139-152), Beverly Hills: Sage.

Dryzek, J. S. (1997). The Politics of the Earth. Environmental Discourses. Oxford: Oxford University Press.

Estabrooks, C. (1999). The conceptual structure of research utilization. Research in Nursing \& Health 22(3): 203-216

Etzioni, A. (1968). The Active Society: A Theory of Societal and Political Processes. New York, NY: The Free Press.

European Commission (2001). European Governance: A White Paper. COM(2001) 428 final. http://eur-lex.europa.eu/LexUriServ/site/en/com/2001/com2001 0428en01.pdf.

European Commission (2008). Scientific Evidence for Policy-making. EUR 22982

EN. Brussels: DG Research, Socio-Economic Sciences and Humanities. ftp://ftp.cordis, europa.eu/pub/fp7/ssh/docs/20080619en.pdf.

Eyestone, R. (1977) Confusion, diffusion and innovation. American Political Science Review 71: 441-447.

Fischer, F. (1990). Technocracy and the Politics of Expertise. Newsbury Park: Sage.

Fischer, F. (2000). Citizens, Experts and the Environment: The Politics of Local Knowledge. Durham, NC: Duke University Press.

Fischer, F. and J. Forester (1993). The Argumentative Turn in Policy Analysis and Planning. Durham, NC: Duke University Press.

Flyvbjerg, B. (2001). Making Social Science Matter: Why Social Inquiry Fails and How it Can Succeed Again. Cambridge: Cambridge University Press.

Foucault, M. (1978). Governmentality. In: P. Rabinow and N. Rose (Eds.), (2003) The Essential Foucault: Selections from Essential Works of Foucault, 1954-1984 (pp. 229-245), New York: The New Press.

Freeman, R. (2006). Learning in public policy. In: M. Moran, M. Rein and R. E. Goodin (eds.) The Oxford Handbook of Public Policy. Oxford: Oxford University Press, pp. 367-388

Freeman, R. and Sturdy, S. (2014). Introduction: knowledge in policy-embodied, inscribed, enacted. In: R. Freeman and S. Sturdy (Eds.), Knowledge in Policy: Embodied, Inscribed, Enacted. Chicago: University of Chicago Press.

Gabbay J. and le May, A. C. (2004). Evidence based guidelines or collectively constructed "mindlines"? Ethnographic study of knowledge management in primary care. $B M$ 329: 1013 .

Gieryn, T. F. (1983). Boundary-work and the demarcation of science from nonscience: strains and interests in professional ideologies of scientists. American Sociological Review 48(6): 781-795.

Glasbergen, P. (1996). "Learning to manage the environment," Democracy and the environment: Problems and prospects, 175-193.

Glaser, G. and Bates, P. (2011). Enhancing Science-Policy Links for Global Sustainability. Report for the Stakeholder Forum.

Gray, J. A. M. (1997). Evidence-based healthcare: How to make health policy and management decisions. New York: Churchill Livingstone.

Guston, D. H. (2001). Boundary organisations in environmental policy and science: an introduction. Science, Technology, and Human Values 26(4): 399-408.

Haas, P. M. (1989). Do regimes matter? Epistemic communities and Mediterranean pollution control. International Organization 43(3): 377-403. 
Haas, P. M. (1992). Epistemic communities and international policy coordination. International Organization 46: 1-35.

Haddow, G. and Klobas, E. (2004). Communication of research to practice in library and information science: closing the gap. Library \& Information Science Research 26: 29-43.

Hajer, M. (1995). The Politics of Environmental Discourse: Ecological Modernization and the Policy Process. Clarendon Press.

Hajer, M. and Laws, D. (2006). Ordering through discourse. In: M. Moran, M. Rein and R. E. Goodin (eds.): The Oxford Handbook of Public Policy. Oxford: Oxford University Press, pp. 251-268.

Hall, P. A. (1993). "Policy paradigms, social learning, and the state: The case of economic policy-making in Britain," Comparative Polics 25: 275-296.

Hall, P. A. (ed.) (1989). The Political Power of Economic Ideas: Keynesianism across Nations. Princeton: Princeton University Press.

Havelock, R. (1969). Planning for Innovation through the Dissemination and Utilization of Scientific Knowledge. Ann Arbor, MI: CRUSK, Institute for Social Research.

Head, B. W. (2010). Reconsidering evidence-based policy: key issues and challenges. Policy and Society 29: 77-94.

Healey, P. (2007). Urban Complexity and Spatial Strategies: Towards a Relational Planning for Our Times. London: Routledge.

Heclo, H. (1974). Modern Social policies in Britain and Sweden: From Relief to Income Maintenance. New Haven: Yale University Press.

Heclo, Hugh. (1974). Modern Social Policy in Britain and Sweden: From Relief to Income Maintenance. New Haven.

Higging, P. T. and Green, S. (Eds.), (2008). Cochrane Handbook for Systematic Reviews of Interventions. Wiley.

Holmes, J. and Lock, J. (2010). Generating the evidence for marine fisheries policy and management. Marine Policy 34: 29-35.

Hoppe, R. (1999). Policy analysis, science and politics: from 'speaking truth to power' to 'making sense together'. Science and Public Policy 26(3): 201-210.

Hoppe, R. (2005). Rethinking the science-policy nexus: from knowledge utilization and science technology studies to types of boundary arrangements. Poiesis \& Praxis 3(3): 199-215.

Hoppe, R. (2009). Scientific advice and public policy: expert advisers' and policymakers' discourses on boundary work. Poiesis and Praxis 6: 235-263.

Hoppe, R., Wesselink, A. and Cairns, R. (2013). Lost in the problem: the role of boundary organisations in the governance of climate change. Wiley Interdisciplinary Reviews: Climate Change 4(4): 283-300.

Hughes, M., Kroehler, C. J. and Vander, J. W. (2002). Sociology: The Core. New York: McGraw Hill.

Jasanoff, S. (1990) The Fifth Branch: Science Advisors as Policy Makers. Harvard University Press.

Jasanoff, S. (1996) Science and norms in global environmental regimes. In: F. Osler Hampson and J. Reppy (Eds.): Earthly Goods: Environmental Change and Social Justice, (pp. 173-197), Ithaca, NY: Cornell University Press.

Jasanoff, S. (1997). Social Learning in the Risk Society. Committee for the Interdisciplinary Environmental Studies. Cambridge: Cambridge University Press.
Jasanoff, S. (Ed.) (2004). States of Knowledge: The Co-production of Science and the Social Order. Routledge.

Jasanoff, S. and Wynne, B. (1998). Science and decision-making. In: S. Rayner and E. Malone (Eds.): Human choice and climate change: an international assessment. Vol. 1: The Societal Framework (pp. 1-112), Columbus, OH: Battelle Press.

Jenkins-Smith, H. C. and P. A. Sabatier (1993). "The dynamics of policy-oriented learning," In: Jenkins-Smith, H. C. and P. A. Sabatier (Eds.) Policy Change and Learning: The Advocacy Coalition Framework. Pp. 41-56.

Jessop, B. (1990). State Theory: Putting the Capitalist State in Its Place. Penn State University Press.

Keller, A. C. (2009). Science in Environmental Policy: The Politics of Objective Advice. Cambridge, MA: MIT Press.

Kingdon, J. W. (1995). Agenda, Alternatives, and Public Policies. 2nd ed. New York: HarperCollins College.

Knorr-Cetina, K. (2007). Culture in global knowledge societies: knowledge cultures and epistemic cultures. Interdisciplinary Science Reviews 32(4): 361-375.

Knott, J. and Wildavsky, A. (1980). If dissemination is the solution, what is the problem? Knowledge: Creation, Diffusion, Utilization 1(4): 537-578.

Kothari, A., MacLean, L. and Edwards, N. (2009). Increasing capacity for knowledge translation: understanding how some researchers engage policy-makers. Evidence and Policy 5(1): 33-51.

Lahsen, M. (2004). Transnational locals: Brazilian experiences of the climate regime. In S. Jasanoff and M. L. Martello (eds.): Earthly Politics: Local and Global in Environmental Governance, (pp. 151-172), Cambridge, MA: MIT Press.

Latour, B. (1986). Visualisation and cognition: drawing things together. In H. Kuklick and E. Long (eds.): Knowledge and Society Studies in the Sociology of Culture Past and Present 6: 1-40.

Latour, B. (1988). Mixing humans and non-humans together: the sociology of a doorcloser. Social Problems 35(3): 298-310.

Lave, J., \& Wenger, E. (1991). Situated Learning: Legitimate Peripheral Participation. Cambridge: Cambridge University Press.

Likens, G. E. (2010). The role of science in decision making: does evidence-based science drive environmental policy? Frontiers in Ecology and the Environment 8(6): e1-e9.

Lindblom, C. (1959). The science of "muddling through". Public Administration Review 19(2): $79-88$

Lipsky, M. (1980). Street level Bureaucracy. New York: Russell Sage.

Lukes, S. (1974). Power: A Radical View. Macmillan: London.

May, P. (1992). Policy learning and failure. Journal of Public Policy 12(4): 331-354.

Meyer, M. (2010). The rise of the knowledge broker. Science Communication 32(1): 118-127.

Meyer, M. and Molyneux-Hodgson, S. (2010). Introduction: the dynamics of epistemic communities. Sociological Research Online 15(2): 14

Michaels, S. (2009). Matching knowledge brokerage strategies to environmental problems and settings. Environmental Science and Policy 12: 994-1011.

Mikulskiene, B. (2013). Research-based Knowledge for Policy Decision Making: Maximizing the Opportunities of Impact. European Integration Studies 7: 35-41. 
Miller, C. A. (2004). Climate science and the making of a global political order. In: Jasanoff, S. (ed.): States of Knowledge: The Co-Production of Science and Social Order. Routledge. Montpetit, E. (2007) Policy Learning in the Midst of Controversy: A Comparative Survey of Biotechnology Policy Actors. Paper presented at the annual meeting of the American Political Science Association, Hyatt Regency Chicago and the Sheraton Chicago Hotel and Towers, Chicago, IL, Aug 30, 2007.

Nassehi, A., von der Hagen-Demszky, A. and Mayr, K. (2007). The Structures of Knowledge and of Knowledge Production. Literature Review and Theoretical Framework Report (Part 8). Know \& Pol project. URL: http://knowandpol.eu/IMG/pdf/lr.tr.nassehi_al.eng. pdf

Nicolini, D., Gherardi, S. and Yanow, D. (2003). Introduction: Toward a Practice-Based View of Knowing and Learning in Organizations. In: D. Nicolini, S. Gherardi and D. Yanow (Eds.), Knowing in Organizations: A Practice-Based Approach (pp. 3-31), Armonk, NY M. E. Sharpe.

Nowotny H., Scott, P. and Gibbons, M. (2003). Introduction: 'Mode 2' revisited: the new production of knowledge. Minerva 41: 179-194.

Nutley, S. M. and Webb, J. (2000). Evidence and the policy process. In: H. Davies, S. M. Nutley and P.C. Smith (Eds.), What Works? Evidence-Based Policy and Practice in Public Services (pp. 13-41), Bristol: The Policy Press.

Nutley, S. M., Walter, I. and Davies, H. T. O. (2007). Using Evidence: How Research Can Inform Public Services. Bristol: The Policy Press.

Oldham, G. and McLean, R. (1997). Approaches to Knowledge-Brokering. International Institute for Sustainable Development. Winnipeg: IISD. URL: http://www.iisd.org/ pdf/2001/networks_knowledge_brokering.pdf

Ottoson, J. M. (2009). Knowledge-for-action theories in evaluation: knowledge utilization, diffusion, implementation, transfer, and translation. New Directions for Evaluation 124 (Winter): 7-20.

Owens, S., Petts, J. and Bulkeley, H. (2006). Boundary work: knowledge, policy, and the urban environment. Environment and Planning C: Government and Policy 24: 633-643.

Page, E. C. and Wright, V. (2007). Introduction: from the active to the enabling state. In: Page, E. C. \& Wright, V. (Eds.), From the Active to the Enabling State: The Changing Role of Top Officials in European Nations (pp. 1-14), Basingstoke: Palgrave Macmillan.

Parsons, W. (1995). Public policy: an introduction to the theory and practice of policy analysis. Edward Elgar Pub.

Parsons, W. (2002). "From Muddling Through to Muddling Up - Evidence Based Policy Making and the Modernization of the British Government. Public Policy and Administration 17 (3): 43-60.

Parsons, W. (2004). Not just steering but weaving: relevant knowledge and the craft of building policy capacity and coherence. Australian Journal of Public Administration 63(1): 43-57.

Pawson, R. (2006). Evidence-Based Policy. A Realistic Perspective. London: Sage

Petts J. and Brooks, C. (2006) Expert conceptualisations of the role of lay knowledge in environmental decisionmaking: challenges for deliberative democracy. Environment and Planning A 38: 1045-1059.

Polanyi, M. (1962). Personal Knowledge: Towards a Post-critical Philosophy. 2nd ed. Chicago: University of Chicago Press.
Pons, X., and van Zanten, A. (2007). Knowledge Circulation, Regulation and Governance. Literature Review and Theoretical Framework Report (Part 6). Know \& Pol project. URL: http://knowandpol.eu/IMG/pdf/lr.tr.pons_vanzanten.eng.pdf

Pregernig, M. (2004). Linking knowledge and action: the role of science in NFP processes. In: P. Glück and J. Voitleithner (Eds.), NFP Research: Its Retrospect and Outlook (pp. 195-215), Vienna: Institute for Forest Sector Policy and Economics.

Reckwitz, A. (2003). Grundelemente einer Theorie sozialer Praktiken: Eine sozialtheoretische Perspektive. Zeitschrift für Soziologie 32(4): 282-301.

Rice, J. L., Burke, B. J. and Heynen, N. (2015). Knowing climate change, embodying climate praxis: experiential knowledge in Southern Appalachia. Annals of the Association of American Geographers 105(2): 1-10.

Rose, R. (1991). "What is lesson-drawing?" Journal of Public Policy, 11, (1), 3-30.

Rose, R. (1993). Lesson-Drawing in Public Policy. A Guide to Learning Across Time and Space, Chatham NJ: Chatham House Publishers.

Rosenberg, W. and Donald, A. (1995). Evidence based medicine: an approach to clinical problem-solving. BMJ 310(6987): 1122-1126.

Rutherford, P. (1999). The entry of life into history. In: É. Darier (Ed.), Discourses of the Environment, (pp. 37-62), Oxford: Blackwell Publishers.

Ryle, G. (1949). The Concept of Mind. Chicago: University of Chicago Press.

Sabatier, P. A. 1988. Knowledge, policy-oriented learning, and policy change an advocacy coalition framework. Science Communication 8(4): 649-692.

Sabatier, P. and H. C. Jenkins-Smith. (1999). The advocacy coalition framework: an assessment, In: Sabatier, P. (Ed.) Theories of the Policy Process. Westview Press.

Sager, F. (2007). Making transport policy work: polity, policy, politics and systematic review. Policy \& Politics, 35(2), 269-288.

Sanderson, I. (2000). Evaluation in Complex Policy Systems. Evaluation 6(4): 433-454.

Schatzki T. R. (2012). A primer on practices. In: J. Higgs, R. Barnett, S. Billett, M. Hutchings and F. Trede (Eds.): Practice-based Education: Perspectives and Strategies, (pp. 13-26) Rotterdam: Sense.

Schön, D. A. and Rein, M. (1994). Frame Reflection: Toward the Resolution of Intractable Policy Controversies. New York: Basic Books.

Shanley, P. and López, C. (2009). Out of the loop: why research rarely reaches policy makers and the public and what can be done. Biotropica 41(5): 535-544.

Sherman, L. W. and Strang, H. (2007). Restorative Justice: The Evidence. London: Smith Institute.

Shulock, N. (1999). The Paradox of policy analysis: if it is not used, why do we produce so much of it? Journal of Policy Analysis and Management 18(2): 226-244.

Sidney, M. S. (2007). Policy formulation: design and tools. In: F. Fischer, G. J. Miller and M. S. Sidney (Eds.), Handbook of Public Policy Analysis: Theory, Politics, and Methods (pp. 79-87), Boca Raton: CRC Press.

Smith, A. F. (1996). Mad cows and ecstasy: chance and choice in an evidence-based society. Royal Statistical Society Series, 159, 367-384.Star, S. L. and Griesemer, J. R. (1989). Institutional ecology, 'translations' and boundary objects: amateurs and professionals in Berkeley's Museum of Vertebrate Zoology, 1907-39. Social Studies of Science 19(3): 387-420. 
Stevens, A. (2011). Telling policy stories: an ethnographic study of the use of evidence in policy-making in the UK. Journal of Social Policy 40(2): 237-255.

Stone, D. (1997). Policy Paradox. The Art of Political Decision Making. New York: Norton \& Company.

Stone, D. (2001). Learning Lessons, Policy Transfer and the International Diffusion of Policy Ideas. CSGR Working Paper No. 69/01.

Stone, D. (2002). Using knowledge: the dilemmas of "bridging research and policy". Compare 32(3): 285-296.

Task Force (1996). Connecting with the World: Priorities for Canadian Internationalism in the 21st Century. Report of a Task Force led by Maurice F. Strong, tasked the IDRC, IISD and NSI. Ottawa. URL: http://idl-bnc.idrc.ca/dspace/bitstream/10625/14538/1/105111 e.pdf

Tingling, P. M. and Brydon, M. J. (2010). Is decision-based evidence making necessarily bad? MIT Sloan Management Review 51(4): 70-76.

van den Hove, S. (2007). A rationale for science-policy interfaces. Futures 39: 807-826.

Wagenaar, H. (2004). 'Knowing' the rules: administrative work as practice. Public Administration Review 6: 643-655.

Wagenaar, H. (2007). Interpretation and intention in policy analysis. In: Fischer, F., Miller, $G$ J., and Sidney, M. S. (eds.) Handbook of Policy Analysis: Theory, Politics, and Methods. Boca Raton, FL: CRC Press, 429-441.

Ward, V., House, A. and Hamer, S. (2009). Knowledge brokering: the missing link in the evidence to action chain? Evidence and Policy 5(3): 267-279.

Weber, M. 1946. From Max Weber: Essays in Sociology. In H. Gerth \& C. Wright Mills (Eds.), New York: Oxford University Press.

Weible, C. M. (2008). Expert-based information and policy subsystems: a review and synthesis. Policy Studies Journal, 36(4), 615-635.

Weingart, P. (2001). Die Stunde der Wahrheit: Zum Verhältnis der Wissenschaft zu Politik, Wirtschaft und Medien in der Wissensgesellschaft. Weilerswilst: Velbrück Wissenschaft.

Weiss, C. (1977). "Research for Policy's Sake: The Enlightenment Function of Social Science Research". Policy Analysis, 3 (4): 531-545.

Weiss, C. H. (1979). The many meanings of knowledge utilization. Public Administration Review 39 (September/October): 426-431.

Weiss, C. H. (1980). Knowledge creep and decision accretion. Knowledge: Creation, Diffusion, Utilization 1(3): 381-404.

Weiss, C. H. (1999). The interface between evaluation and public policy. Evaluation 5(4): 468-486.

Weiss, C. H., Murphy G. E., Petrosino, A. and Ghandi, A. G. (2008). The fairy godmother and her warts: making the dream of evidence-based policy come true. American Journal of Evaluation 29(1): 29-47.

Wenger, E. (1998). Communities of Practice: Learning, Meaning and Identity. Cambridge: Cambridge University Press.

Wildavsky, A. (1979). Speaking Truth to Power: The Art and Craft of Policy Analysis. Boston: Little, Brown

Wynne, B. (1991). Knowledge in Context. Science, Technology and Human Values 16 $111-121$
Wynne, B. (1996). May the sheep safely graze? A reflexive view of the expert-lay knowledge divide. In: S. Lash, B. Szerszynski and B. Wynne (eds.): Risk, environment and modernity: towards a new ecology. London: Sage, 44-83. 